\title{
CARACTERÍSTICAS ESTRUCTURALES DE LOS HOGARES AGRÍCOLAS CHILENOS: UNA TIPOLOGÍA DE LOS HOGARES RURALES Y DETERMINANTES DE INGRESO EN BASE
}

\author{
A LA ENCUESTA CASEN 2003*
}

\section{William Foster y Alberto Valdés}

\begin{abstract}
El objetivo de este estudio es contribuir a identificar políticas públicas que fomenten un desarrollo más integrador de los hogares de bajos ingresos dependientes de la agricultura, facilitando su acceso a oportunidades de mayores ingresos tanto dentro como fuera del sector. No existe un criterio estándar para definir estos hogares, y por tanto los resultados pueden ser sensibles a la definición empleada, lo que se discute en el texto. En base a la encuesta Casen 2003, el estudio clasifica los hogares agrícolas en dos grandes grupos: independientes (por cuenta propia), usualmente referidos como agricultura familiar, y asalariados. Del análisis realizado se desprende que, asociado al auge agroexportador, la categoría de asalariados es cada vez más importan-
\end{abstract}

William Foster. Ph. D. Agric. Economics, University of California, Berkeley. Profesor del Departamento de Economía Agraria, Facultad de Agronomía, Universidad Católica de Chile.

Alberto ValdÉs. Ph.D. Economics, London School of Economics. Investigador asociado, Universidad Católica de Chile.

* Los autores agradecen especialmente a Rodrigo Rivera por su excelente colaboración y contribución al trabajo estadístico de este estudio, y a Jonathan Brooks y Mauro Migotto de la OCDE por sus comentarios detallados sobre el análisis de la encuesta Casen, así como a los participantes del Taller Sobre Agricultura Chilena organizado por ODEPA en Santiago en abril de 2007.

Traducción al castellano por Carlos Elton para Estudios Públicos.

Estudios Públicos, 113 (verano 2009). 
te, representando cerca del $60 \%$ de los hogares, y en donde aparece una incidencia de pobreza relativamente mayor.

Con todo, se observa que aparte de esas dos grandes categorías existe también una gran heterogeneidad dentro de cada una de ellas, lo que es importante desde el punto de vista del diseño de las políticas públicas. No hay soluciones únicas para los pequeños propietarios. El estudio presenta un perfil desagregado de características de los hogares, considerando localización, nivel de escolaridad y edad del jefe del hogar, como también su género y pertenencia a etnia indígena, y diversas otras variables. Con el objeto de cuantificar el impacto de las distintas características estructurales y demográficas en los ingresos de los hogares, el estudio presenta estimaciones econométricas de funciones de ingreso familiar que dan un orden de magnitud del impacto en el ingreso de cada uno de los atributos analizados.

Palabras clave: Hogares agrícolas; variables socioeconómicas; Chile. Recibido: septiembre de 2008. Aceptado: diciembre de 2008.

\section{Introducción:}

\section{Las características de los hogares agrícolas de bajos ingresos}

$\amalg_{\text {ste trabajo se centra en los hogares de bajos ingresos que depen- }}$ den de la agricultura para su sustento. La incidencia de pobreza -la proporción de la población que es pobre- es más alta entre la fuerza de trabajo agrícola (llegando al 17\% de los trabajadores agrícolas independientes y asalariados) que en el caso de otros sectores de la economía. Por otro lado, entre los pobres que viven en áreas rurales, el 77\% de ellos está empleado en la agricultura. Entre los hogares agrícolas identificamos dos grupos diferenciados: independientes, que representan lo que se suele llamar agricultura familiar, y asalariados. En Chile, el segundo grupo se ha vuelto cada vez más importante debido al aumento de la producción y exportaciones agroalimentarias intensivas en mano de obra.

El objetivo de este estudio es ayudar a identificar políticas públicas que puedan fomentar un desarrollo más integrador de los hogares dependientes de la agricultura, por la vía de facilitar su acceso a oportunidades de mayores ingresos, sea dentro o fuera de la agricultura. Hay enormes vacíos en nuestro conocimiento de las características estructurales y demográficas de los hogares agrícolas de bajos ingresos y, por ende, de las restricciones y oportunidades que ellos enfrentan para alcanzar estándares de vida más altos. 
Las políticas públicas en Chile deberían considerar la heterogeneidad del sector agrícola. Características regionales y diferencias en el tamaño de los predios, en habilidades y capacitación, en acceso a infraestructura, como también en factores demográficos tales como edad, género y etnicidad, significan que las oportunidades y restricciones que enfrenta la población agrícola varían enormemente, y que no hay soluciones únicas para los pequeños propietarios agrícolas. Con el fin de identificar esta heterogeneidad desarrollamos una tipología que ofrece una perspectiva desglosada de los hogares agrícolas y, a continuación, reportamos los principales resultados de estimaciones econométricas diseñadas para cuantificar el impacto de las distintas características estructurales y demográficas en los ingresos de los hogares.

En el análisis utilizamos principalmente dos fuentes de información: el Censo Agropecuario de 1997, que proporciona información adecuada sobre la estructura de producción, pero que ya es algo antigua (amén de contener poca información sobre las características de los hogares), y la encuesta Casen de 2003, la última disponible cuando efectuamos el estudio.

Comenzamos examinando, en la sección 2, lo que se sabe actualmente sobre la fuerza de trabajo chilena en áreas rurales y urbanas, mostrando las cifras de las fuerzas de trabajo agrícola y no agrícola y su distribución geográfica. Luego, en la sección 3, presentamos una tipología de las familias agrícolas, construida en base al Censo Agropecuario de 1997, la que entrega una visión general del número de explotaciones agrícolas según tamaño y uso del suelo, su distribución por macro-regiones, la factibilidad de comercializar la producción de las explotaciones pequeñas y fuentes de ingreso agrícola y no agrícola de la población cuyos ingresos provienen mayoritariamente de la agricultura. La sección 4 incorpora información más reciente, tomada de la encuesta Casen 2003, con el fin de identificar hogares según producción agrícola y trabajo agrícola asalariado, y la dependencia del hogar de fuentes de ingreso agrícola. La sección 5 discute el perfil de pobreza de los hogares agrícolas y luego gira a un análisis econométrico de las ecuaciones de ingreso del hogar, características familiares asociadas a variaciones en el ingreso per cápita familiar. La sección 6 resume los resultados del estudio.

\section{La fuerza de trabajo rural y urbana}

Quién trabaja dónde y en qué sectores

La composición de la fuerza de trabajo agrícola chilena ha cambiado en las últimas décadas según ha evolucionado la composición de la producción. La fuerza de trabajo agrícola ha crecido mucho más lento que la fuerza 
no agrícola (5,5\% contra 40\% entre 1990 y 2003). En 1990, la agricultura empleaba al 17,3\% del total de la fuerza de trabajo del país, al 22,8\% de todos los trabajadores hombres y al 5,4\% de las mujeres. Hacia el año 2003, sin embargo, la agricultura empleaba relativamente a menos hombres y relativamente a más mujeres: representaba el 13,3\% de todos los empleados, el $17,2 \%$ de todos los hombres trabajadores y el 6,5\% de todas las mujeres trabajadoras del país. Hay que tener en cuenta, a su vez, que estas cifras no incluyen el trabajo agroindustrial fuera de las explotaciones agrícolas, el que ha crecido significativamente en el último tiempo desplazando a los cultivos tradicionales, y en el que trabajan principalmente mujeres, en forma temporal o estacional. El número absoluto de hombres empleados en la agricultura aumentó significativamente (en casi 50\%) tras las reformas económicas iniciadas a fines de los años setenta $-\mathrm{y}$, de hecho, durante algunos años la migración se revirtió desde la ciudad al campo-, pero desde fines de los años ochenta ha ido disminuyendo en forma gradual. En contraste, desde comienzos de los ochenta el número absoluto de mujeres empleadas en la agricultura ha aumentado sobre el 350\%.

Mientras el empleo rural no agrícola ha crecido en Chile con el desarrollo económico, el grueso de la demanda de trabajo en el sector rural todavía se orienta hacia la agricultura: en 1990 la agricultura representaba el $73 \%$ de la fuerza de trabajo rural, según la definición oficial, y en 2003 el 65\%. Pero, cabe advertir, también ha cambiado la composición del empleo en el sector agrícola en lo que respecta a trabajadores asalariados versus trabajadores independientes (trabajadores por cuenta propia). De toda la fuerza de trabajo agrícola, que aumentó en 5,1\% entre 1990 y 2003, los trabajadores asalariados constituyen el 68\% —algo más que en el caso de la fuerza laboral no agrícola, una proporción relativamente alta si se compara con otros países en la región. El número de trabajadores agrícolas asalariados aumentó 9,6\% entre 1996 y 2003. Es importante notar que la proporción de los trabajadores asalariados en el sector agrícola es mayor (alcanzando sobre el 80\%) en aquellas regiones del país en que ha habido un boom de la horticultura orientada a las exportaciones, y sus números absolutos han aumentado a una tasa mucho mayor que en otras regiones. A la inversa, en las áreas de producción asociadas a las cosechas tradicionales (que compiten con importaciones, como por ejemplo, trigo, leche y carne) el número de trabajadores asalariados ha disminuido desde 1990. A su vez, el empleo agrícola parece tender a una mayor estacionalidad: en 2003, el 53\% de todos los trabajadores asalariados en la agricultura decía tener un trabajo temporal (lo que incluye trabajos estacionales), comparado con el $47 \%$ en 1994 . Con 
respecto a las mujeres, en su mayoría trabajadoras estacionales, en 1994 la proporción ya era alta, 72\%, y aumentó levemente a 73\% en $2003^{1}$.

Quizá sea sorprendente que muchas personas empleadas en la agricultura vivan ahora en áreas urbanas (43\%), pero esto varía según las localidades geográficas. En 2003, de un total de 788.873 personas clasificadas como fuerza de trabajo agrícola, 450.971 vivían en áreas rurales, mientras que 337.902 vivían en áreas urbanas. La fuerza de trabajo rural no agrícola asciende a 255.150 personas (Tabla $N^{\circ} 1$ ). La zona central (regiones V a VII y la Región Metropolitana), donde se ubica principalmente el sector orientado a las exportaciones, constituye el 64\% de la fuerza de trabajo agrícola.

Una comparación de la fuerza de trabajo agrícola con otros sectores se presenta en la Tabla $N^{o}$ 2, donde se puede apreciar la distribución de las

TABLA N ${ }^{\circ}$ 1: $\quad$ LA FUERZA DE TRABAJO AGRÍCOLA Y NO AGRÍCOLA SEGÚN LUGAR DE RESIDENCIA Y REGIÓN, 2003

\begin{tabular}{|c|c|c|c|c|c|c|c|c|c|}
\hline \multirow[t]{3}{*}{ Región } & \multicolumn{3}{|c|}{ Fuerza de trabajo agrícola } & \multicolumn{3}{|c|}{ Fuerza de trabajo no agrícola } & \multicolumn{3}{|c|}{ Total } \\
\hline & \multicolumn{3}{|c|}{ Residencia } & \multicolumn{3}{|c|}{ Residencia } & \multicolumn{3}{|c|}{ Residencia } \\
\hline & Urbana & Rural & Total & Urbana & Rural & Total & Urbana & Rural & Total \\
\hline I & 6.946 & 4.760 & 11.706 & 148.740 & 3.462 & 152.202 & 155.686 & 8.222 & 163.908 \\
\hline II & 6.650 & 1.015 & 7.665 & 182.126 & 1.641 & 183.767 & 188.776 & 2.656 & 191.432 \\
\hline III & 11.101 & 3.749 & 14.850 & 78.175 & 2.662 & 80.837 & 89.276 & 6.411 & 95.687 \\
\hline IV & 22.434 & 29.694 & 52.128 & 160.705 & 17.887 & 178.592 & 183.139 & 47.581 & 230.720 \\
\hline V & 40.510 & 31.164 & 71.674 & 491.491 & 20.327 & 511.818 & 532.001 & 51.491 & 583.492 \\
\hline R.M. & 69.172 & 36.227 & 105.399 & 2.502 .100 & 41.730 & 2.543 .830 & 2.571 .272 & 77.957 & 2.649.229 \\
\hline VI & 42.856 & 58.969 & 101.825 & 181.179 & 28.064 & 209.243 & 224.035 & 87.033 & 311.068 \\
\hline VII & 31.816 & 78.576 & 110.392 & 205.024 & 37.142 & 242.166 & 236.840 & 115.718 & 352.558 \\
\hline VIII & 48.205 & 70.556 & 118.761 & 495.148 & 33.054 & 528.202 & 543.353 & 103.610 & 646.963 \\
\hline IX & 17.440 & 57.811 & 75.251 & 187.077 & 25.583 & 212.660 & 204.517 & 83.394 & 287.911 \\
\hline $\mathrm{X}$ & 31.946 & 73.402 & 105.348 & 246.944 & 39.936 & 286.880 & 278.890 & 113.338 & 392.228 \\
\hline XI & 4.425 & 3.713 & 8.138 & 26.524 & 2.749 & 29.273 & 30.949 & 6.462 & 37.411 \\
\hline XII & 4.401 & 1.281 & 5.682 & 53.873 & 913 & 54.786 & 58.274 & 2.194 & 60.468 \\
\hline Total & 337.902 & 450.917 & 788.819 & 4.959.106 & 255.150 & 5.214 .256 & 5.297.008 & 706.067 & 6.003.075 \\
\hline
\end{tabular}

Fuente: Elaboración de los autores en base a la encuesta Casen 2003.

${ }^{1}$ Las estadísticas citadas en este párrafo y en el precedente son obtenidas de cálculos de los autores basándose en la información de las encuestas periódicas a los hogares desde 1987 (encuesta de Caracterización Socioeconómica, Casen) y encuestas sobre empleo realizadas por el INE (Instituto Nacional de Estadísticas de Chile). 


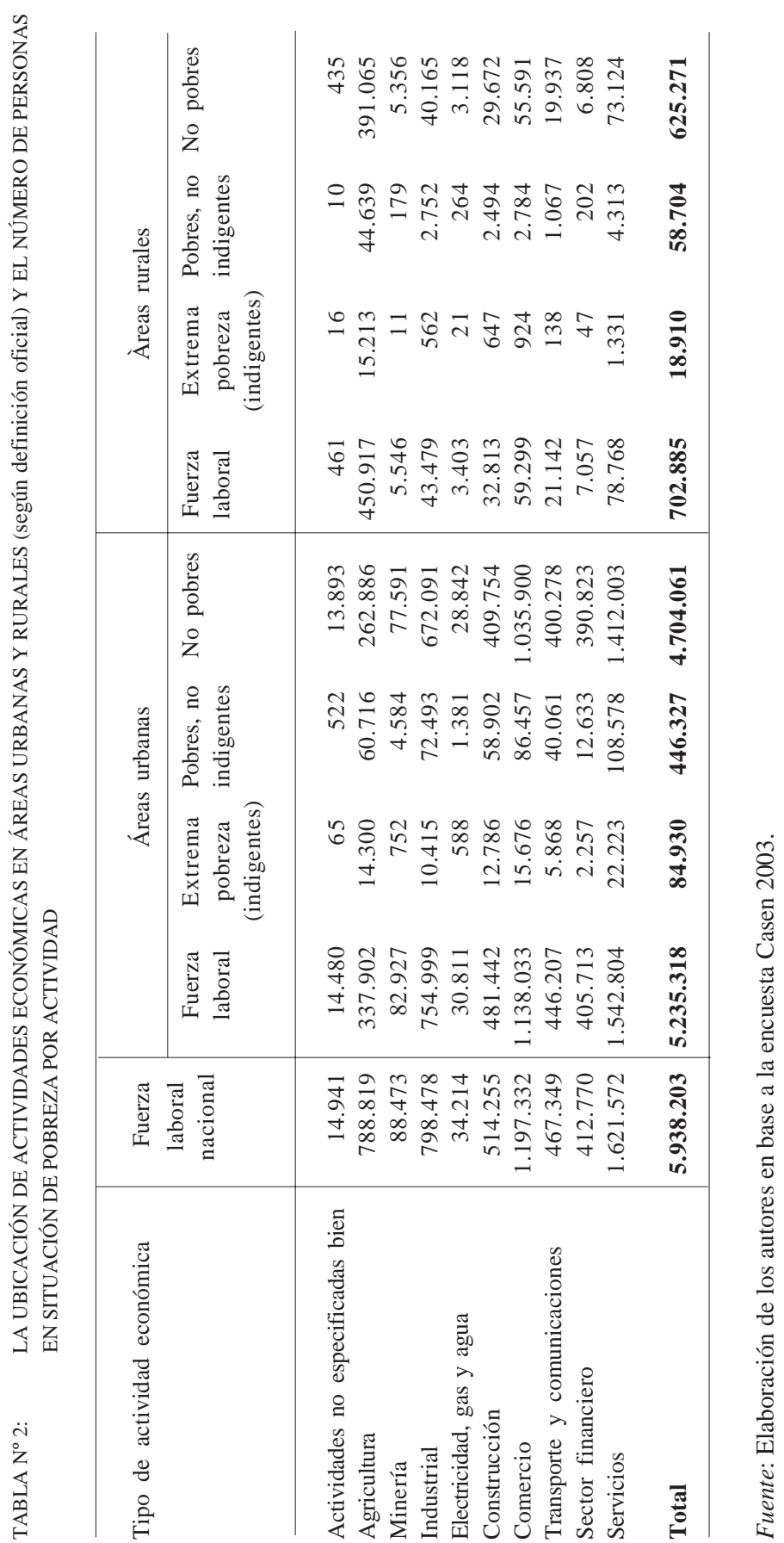


distintas fuerzas de trabajo sectoriales en áreas rurales y urbanas. Más importante, para efectos de políticas públicas, es saber dónde viven los pobres y qué están haciendo. Las tasas de pobreza dentro de la fuerza de trabajo en áreas rurales son apenas más altas que en áreas urbanas (11\% y $10 \%$ respectivamente), pero las tasas de pobreza en la fuerza de trabajo agrícola (17\%) son mucho mayores que el promedio de toda la fuerza de trabajo (Tabla $\left.\mathrm{N}^{\circ} 2\right)^{2}$. Cabe destacar que de acuerdo a la encuesta Casen 2003 hay tantos indigentes que trabajan en la agricultura viviendo en áreas rurales como en áreas urbanas, conforme con la definición oficial de ruralidad. La incidencia de la pobreza - la proporción de pobres - es más alta entre la fuerza de trabajo agrícola (ya sean independientes o trabajadores asalariados) que en otros sectores de la economía. De hecho, el grueso de los pobres rurales (77\%), entre indigentes y no indigentes, se encuentran empleados, cuando tienen empleo, en la agricultura. El 17\% de la fuerza del trabajo en el sector agrícola es pobre. Si bien hay menos pobres en áreas rurales por recuento de personas que en áreas urbanas, la pobreza es más aguda: el $16 \%$ de todos los pobres en las áreas urbanas son indigentes versus el $24 \%$ en las áreas rurales. Cabe advertir al lector no familiarizado con las definiciones oficiales de urbano y rural, que no todos los pobres urbanos viven en barrios marginales de las grandes ciudades. De hecho, aun cuando hay concentración de pobres en ciertas áreas de las grandes ciudades, muchos de ellos viven en lo que cabría considerar como pequeños pueblos en sectores donde la agricultura es importante: los 75.000 pobres que viven en zonas urbanas y que trabajan en agricultura son un claro ejemplo de esto ${ }^{3}$.

\section{Información previa: \\ Tipología de las explotaciones agrícolas familiares en base al Censo Agropecuario de 1997}

A continuación resumiremos brevemente algunos resultados de un estudio sobre explotaciones agrícolas pequeñas en Chile, preparado en 2006 por Melo y López de Lérida (de la Pontificia Universidad Católica de Chile)

\footnotetext{
${ }^{2}$ Resultados preliminares de la encuesta Casen 2006 informan una reducción de la pobreza en áreas rurales respecto de áreas urbanas.

${ }^{3}$ La proporción de la población rural en Chile aumentaría el doble si uno acepta una redefinición de qué es rural mediante la incorporación de densidad de población y tiempo de viaje a una ciudad grande. El análisis se presenta en De Ferranti, Perry, Foster, Lederman y Valdés: "Beyond the City: The Rural Contribution to Development in Latin America”, 2005.
} 
y patrocinado por la FAO y el BID. El estudio utiliza el Censo Agropecuario de 1997 para determinar el número de explotaciones agrícolas pequeñas. Y para establecer las características de los hogares en el sector agrícola, el estudio combinó datos de explotaciones agrícolas encuestadas para el Censo Agropecuario con los datos recogidos por las encuestas Casen de 1996 y 1998. Esto permitió asociar características de producción de las explotaciones agrícolas con las de los hogares agrícolas independientes. El estudio clasifica primero a las explotaciones agrícolas pequeñas, como aquellas que producen en un cierto número máximo de hectáreas — dependiendo su tamaño específico de la zona agro-ecológica en que se encuentran- y que tienen menos de diez empleados. Estas explotaciones agrícolas pequeñas son subclasificadas como de "subsistencia”, "transición” y "consolidadas”, según el número y tipo de trabajadores contratados. Las explotaciones agrícolas de subsistencia no contratan empleados. Las explotaciones agrícolas de transición contratan trabajadores, pero no tienen administradores. Las explotaciones agrícolas consolidadas contratan administradores. La cantidad y tamaño de dichas explotaciones agrícolas se pueden apreciar en las Tablas $\mathrm{N}^{\mathrm{os}}$ 3a y 3b. La Tabla $\mathrm{N}^{\circ}$ 3c muestra la distribución de los distintos tipos de explotaciones agrícolas por macro-región, y la Tabla $\mathrm{N}^{\circ} 3 \mathrm{~d}$ da algunos detalles en relación con el uso del suelo.

TABLA No 3a:

TIPOLOGÍA DE EXPLOTACIONES AGRÍCOLAS EN BASE AL CENSO AGROPECUARIO DE CHILE DE 1997

\begin{tabular}{l|ccc}
\hline $\begin{array}{l}\text { Tipo de explotación } \\
\text { agrícola }\end{array}$ & $\begin{array}{c}\text { Número de } \\
\text { productores }\end{array}$ & $\begin{array}{c}\text { Proporción del } \\
\text { total nacional (\%) }\end{array}$ & $\begin{array}{c}\text { Proporción relativa } \\
\text { a todos los pequeños } \\
\text { propietarios (\%) }\end{array}$ \\
\hline Subsistencia & 154.820 & 47,6 & 54,4 \\
$\begin{array}{l}\text { Transición } \\
\text { Consolidada }\end{array}$ & 120.626 & 37,1 & 42,4 \\
$\begin{array}{l}\text { Total explotaciones } \\
\text { agrícolas pequeñas }\end{array}$ & 8.942 & 2,7 & 3,1 \\
$\begin{array}{l}\text { Explotaciones agrícolas } \\
\text { más grandes }\end{array}$ & 284.388 & 87,4 & 100 \\
$\quad$ Total & 325.515 & 12,6 & \\
\hline
\end{tabular}

Fuente: Melo y López de Lérida (2006) en base al Censo Agropecuario de 1997. 
TABLA N ${ }^{\circ}$ 3b: TAMAÑO DE LAS EXPLOTACIONES AGRÍCOLAS Y HECTÁREAS TOTALES POR TIPO DE EXPLOTACIÓN AGRÍCOLA EN BASE AL CENSO AGROPECUARIO DE CHILE DE 1997

\begin{tabular}{|c|c|c|c|c|}
\hline $\begin{array}{l}\text { Tipo de predio } \\
\text { agrícola }\end{array}$ & $\begin{array}{c}\text { Tamaño } \\
\text { promedio de } \\
\text { la explotación } \\
\text { agrícola (ha) }\end{array}$ & $\begin{array}{l}\text { Superficie } \\
\text { total } \\
\text { (1.000 ha) }\end{array}$ & $\begin{array}{l}\text { Proporción del } \\
\text { total nacional } \\
\text { (\%) }\end{array}$ & $\begin{array}{c}\text { Proporción } \\
\text { relativa a todos } \\
\text { los pequeños } \\
\text { propietarios (\%) }\end{array}$ \\
\hline Subsistencia & 17,16 & 2.656 & 5,18 & 41,12 \\
\hline Transición & 26,65 & 3.214 & 6,27 & 49,76 \\
\hline Consolidada & 65,90 & 589 & 1,15 & 9,12 \\
\hline $\begin{array}{l}\text { Total explotaciones } \\
\text { agrícolas pequeñas }\end{array}$ & 22,71 & 6.460 & 12,59 & 100 \\
\hline $\begin{array}{l}\text { Explotaciones } \\
\text { agrícolas más grandes }\end{array}$ & $1.090,29$ & 44,80 & 87,41 & \\
\hline Total & 155,66 & 51.300 & 100 & \\
\hline
\end{tabular}

Fuente: Melo y López de Lérida (2006) en base al Censo Agropecuario de 1997. Nótese que éstas son las hectáreas totales de las explotaciones agrícolas medidas, pero no ajustadas por diferencias en la capacidad productiva de la tierra. Nótese también que estas estadísticas son para operaciones agrícolas bajo una administración unificada (explotaciones). Estas explotaciones pueden tener una o más unidades productivas (predios) registradas, las que son tratadas separadamente por el Censo y el sistema de títulos de bienes raíces; estas unidades productivas pueden ser contiguas o pueden estar separadas geográficamente dentro de la misma provincia, pero no pueden traspasar los límites provinciales.

¿Identifica el Censo Agropecuario de 1997 a las familias agrícolas?

El lector debe tener en cuenta que estas explotaciones agrícolas no están necesariamente asociadas con hogares que dependen del ingreso agrícola, ni incluso con hogares cuyos ingresos dependen en forma importante de la agricultura. Familias con jefes de hogar u otros miembros de la familia que trabajan en actividades distintas de la agrícola pueden ser dueñas de explotaciones agrícolas que son consideradas en el Censo Agropecuario. Algunas explotaciones agrícolas pueden ser clasificadas como grandes simplemente por exceder los umbrales de tamaño, aunque sean pequeñas en términos de producción o fuente de ingresos. El conteo de las explotaciones agrícolas familiares a partir del Censo podría probablemente exagerar su número, particularmente en el caso de las explotaciones agrícolas de "subsistencia” y "más grandes", como se verá en la discusión del número de hogares agrícolas en base a la información de la encuesta Casen. En el Censo, la cantidad de explotaciones agrícolas dentro de la categoría de 
TABLA No 3c: $\quad$ NÚMERO Y PORCENTAJE DE EXPLOTACIONES AGRÍCOLAS PEQUEÑAS POR MACRO-ZONA Y TIPO DE EXPLOTACIÓN AGRÍCOLA SEGÚN EL CENSO AGROPECUARIO DE 1997

\begin{tabular}{l|rrr|r}
\hline \multirow{2}{*}{ Macro-zona } & \multicolumn{2}{|c|}{ Tipo de explotación agrícola } & \multirow{2}{*}{$\begin{array}{c}\text { Total } \\
\text { explotaciones }\end{array}$} \\
\cline { 2 - 3 } agrícolas pequeñas \\
\cline { 2 - 3 } Norte & Subsistencia & Transición & Consolidada & \\
\cline { 2 - 3 } Zona central & 10.915 & 8.825 & 622 & 20.362 \\
& $(53,60 \%)$ & $(43,34 \%)$ & $(3,05 \%)$ & $(100 \%)$ \\
Sur & 43.026 & 47.357 & 4.575 & 94.958 \\
Total nacional & $(45,31 \%)$ & $(49,87 \%)$ & $(4,82 \%)$ & $(100 \%)$ \\
& 100.879 & 64.444 & 3.745 & 169.068 \\
& $(59,67 \%)$ & $(38,12 \%)$ & $(2,22 \%)$ & $(100 \%)$ \\
& 154.820 & 120.626 & 8.942 & 284.388 \\
& $(54,44 \%)$ & $(42,42 \%)$ & $(3,14 \%)$ & $(100 \%)$ \\
\hline
\end{tabular}

Fuente: Melo y López de Lérida (2006), en base al Censo Agropecuario de 1997. Nótese que estas estadísticas son para operaciones de explotaciones agrícolas bajo una administración unificada (explotaciones). Estas explotaciones pueden tener una o más unidades productivas (predios) registradas, las que son tratadas separadamente por el Censo y el sistema de títulos de bienes raíces; estas unidades productivas pueden ser contiguas o pueden estar separadas geográficamente dentro de la misma provincia, pero no pueden traspasar los límites provinciales.

pequeñas es mucho mayor que el número de hogares cuyo jefe se clasifica a sí mismo como trabajador agrícola independiente en la encuesta Casen.

No obstante, la información sobre los jefes de hogar agrícolas independientes de la encuesta Casen se puede cotejar con la del Censo y ver así la conexión entre la estructura de las explotaciones agrícolas y el ingreso del hogar de las familias agrícolas. La presunción básica es que casi todas las explotaciones agrícolas se encuentran registradas en el Censo Agropecuario, que incluye un número mayor que la población de las explotaciones agrícolas familiares. De modo que si la encuesta Casen entrevista al dueño de una explotación agrícola (alguien que responde que él o ella trabaja de manera independiente en la agricultura) en una fecha cercana al Censo, la información sobre producción de dicho predio agrícola debiera estar en el Censo. Hay una alta probabilidad de que el dueño de una explotación agrícola según la encuesta Casen sea la misma persona que en el Censo aparece con idénticas características (misma ubicación, misma edad, mismo nivel de educación, mismo número y edades de los miembros del hogar). 
TABLA N ${ }^{\circ} 3 \mathrm{~d}$ : CARACTERÍSTICAS DE LAS EXPLOTACIONES AGRÍCOLAS SEGÚN TIPOS DEL CENSO AGROPECUARIO DE 1997

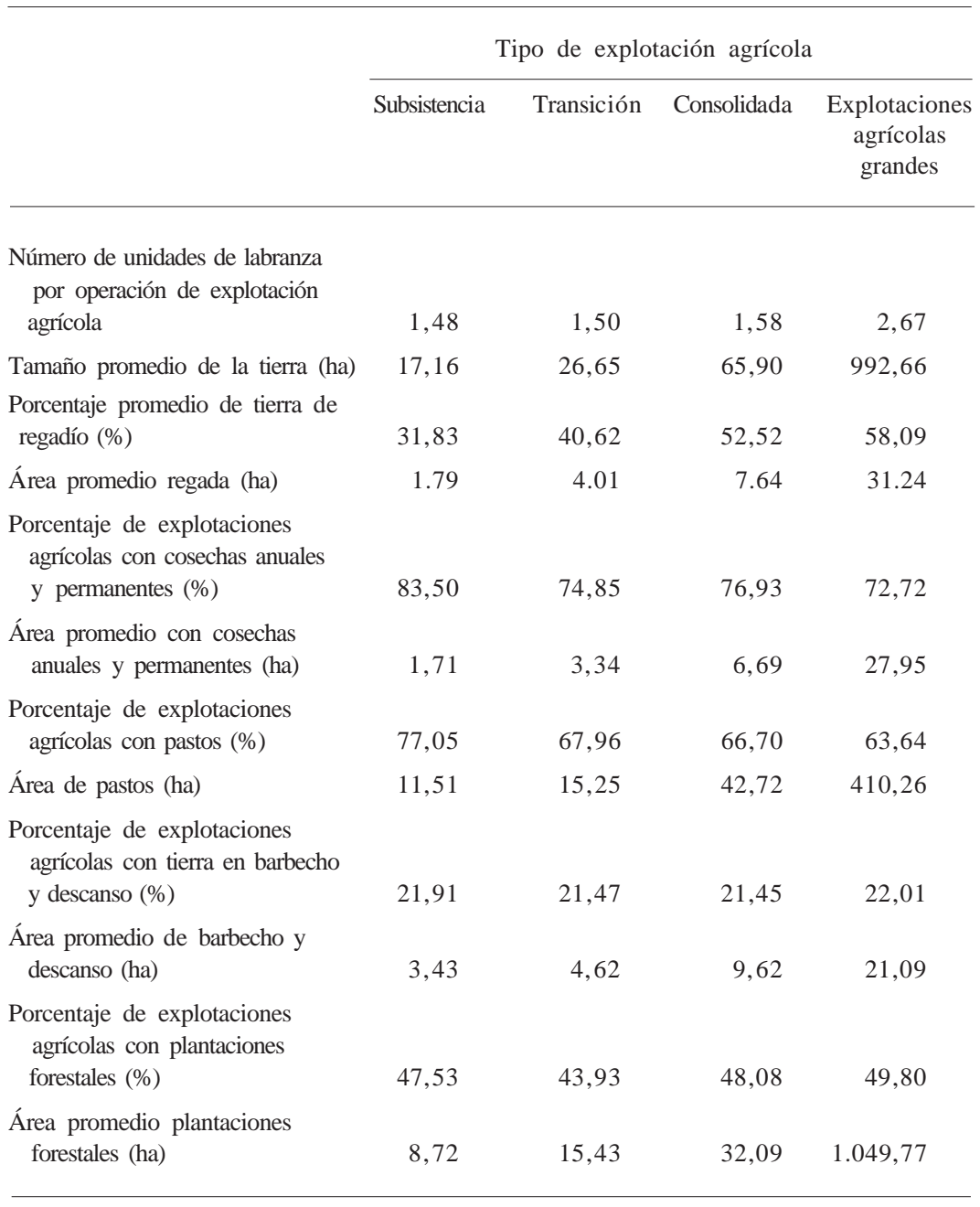

Fuente: Melo y López de Lérida (2006) en base al Censo Agropecuario de 1997. Nótese que estas estadísticas son para operaciones de explotaciones agrícolas bajo una administración unificada (explotaciones). Estas explotaciones pueden tener una o más unidades productivas (predios) registradas, las que son tratadas separadamente por el Censo y el sistema de títulos de bienes raíces; estas unidades productivas pueden ser contiguas o pueden estar separadas geográficamente dentro de la misma provincia, pero no pueden traspasar los límites provinciales. 
Caracterización de las explotaciones agrícolas pequeñas del Censo Agropecuario de 1997

Adoptando esta clasificación, y con las advertencias precedentes, ¿qué se puede decir en base al Censo? El número de explotaciones agrícolas pequeñas (de todos los tipos) no cambió mucho en los últimos treinta años, aunque el número de operaciones "precarias" (ocupantes ilegales y aparceros) ha disminuido significativamente. En términos de cosechas y praderas, las explotaciones agrícolas de subsistencia tienen cada una en promedio 17,1 hectáreas, las de transición 26,6 hectáreas y las consolidadas 65,9 hectáreas. En términos de tierra regada, las explotaciones agrícolas pequeñas de subsistencia tienen 1,8 ha, las de transición 4,0 ha, y las consolidadas 7,6 ha. (En términos del total nacional de tierra de cultivo: el 5,2\% corresponde a explotaciones de subsistencia; 6,3\% a explotaciones de transición y 1,1\% a explotaciones consolidadas.) En 1997, la proporción de la producción agrícola con valor agregado se estimó en 28\% del PGB agrícola. Las explotaciones agrícolas pequeñas están concentradas geográficamente, ubicándose en el sur del país el 65\% de las explotaciones de subsistencia, el $53 \%$ de las explotaciones de transición y el $42 \%$ de las explotaciones consolidadas.

Las explotaciones agrícolas pequeñas se dedican con mayor frecuencia a la producción de cereales (principalmente trigo) y papas, aunque en la zona central las explotaciones agrícolas consolidadas también producen fruta y uva de vino. Los pequeños propietarios también suelen producir carne y leche. Es importante destacar que las explotaciones agrícolas de subsistencia se concentran fuertemente en actividades no comerciables y que compiten con las importaciones, y las explotaciones agrícolas consolidadas se concentran en actividades orientadas a la exportación (Tabla $\mathrm{N}^{\circ} 4$ ). Las fuentes de ingreso aparecen en la Tabla $N^{\circ} 5$. En 1997, el ingreso del trabajo del hogar agrícola (fuera de la explotación agrícola) constituía una parte pequeña del ingreso del hogar, variando de $8 \%$ en las explotaciones consolidadas a un $12 \%$ en las de subsistencia. Estas cifras son bajas si se compara con otros países.

Aunque no hay evidencia directa sobre los patrones de gasto de los hogares agrícolas, Melo y López de Lérida (2006) examinaron los gastos por hogar de la encuesta de Presupuestos Familiares de 1997 del INE. Los hogares de las explotaciones agrícolas de subsistencia y transición están principalmente dentro del segundo quintil, y los hogares de las explotaciones consolidadas en el tercero. La comida representa para los hogares de subsistencia y transición aproximadamente el $40 \%$ del gasto total, del cual los 
TABLA No 4: $\quad$ PROPORCIÓN DEL VALOR TOTAL DE LA PRODUCCIÓN (en porcentaje) POR CLASIFICACIÓN DE COMERCIO Y TIPO DE PEQUEÑO PROPIETARIO SEGÚN EL CENSO AGROPECUARIO DE 1997

\begin{tabular}{l|ccc|c}
\hline $\begin{array}{l}\text { Clase de comercio } \\
\text { agrícola }\end{array}$ & Subsistencia & Transición & Consolidada & $\begin{array}{c}\text { Todos los } \\
\text { pequeños } \\
\text { propietarios }\end{array}$ \\
\hline Exportables & 17 & 24 & 46 & 24 \\
Importables & 39 & 45 & 35 & 42 \\
No comerciables & 44 & 31 & 19 & 34 \\
Todos los productos & 100 & 100 & 100 & 100 \\
\hline
\end{tabular}

Fuente: Melo y López de Lérida (2006) en base al Censo Agropecuario de 1997.

TABLA No 5: $\quad$ FUENTES DE INGRESO DE FAMILIAS CHILENAS DE PEQUEÑAS EXPLOTACIONES AGRÍCOLAS SEGÚN PAREO ENTRE EL CENSO AGROPECUARIO DE 1997 Y 1996 Y LA ENCUESTA CASEN DE 1998

\begin{tabular}{|c|c|c|c|c|}
\hline \multirow{2}{*}{$\begin{array}{l}\text { Fuentes de ingresos por } \\
\text { actividad }\end{array}$} & \multicolumn{3}{|c|}{ Tipología } & \multirow{2}{*}{$\begin{array}{c}\text { Todos los } \\
\text { pequeños } \\
\text { propietarios }\end{array}$} \\
\hline & Subsistencia & Transición & Consolidada & \\
\hline Ingresos de producción agrícola & $75 \%$ & $73 \%$ & $77 \%$ & $74 \%$ \\
\hline Cereales & $32 \%$ & $27 \%$ & $12 \%$ & $27 \%$ \\
\hline Silvicultura & $5 \%$ & $7 \%$ & $8 \%$ & $6 \%$ \\
\hline Fruta & $11 \%$ & $11 \%$ & $25 \%$ & $12 \%$ \\
\hline Horticultura & $15 \%$ & $12 \%$ & $6 \%$ & $13 \%$ \\
\hline Viñas & $2 \%$ & $5 \%$ & $12 \%$ & $5 \%$ \\
\hline Ganado & $11 \%$ & $11 \%$ & $14 \%$ & $11 \%$ \\
\hline $\begin{array}{l}\text { Salarios del trabajo en } \\
\text { explotación agrícola }\end{array}$ & $4 \%$ & $2 \%$ & $4 \%$ & $3 \%$ \\
\hline Total agricultura & $79 \%$ & $75 \%$ & $81 \%$ & $77 \%$ \\
\hline Salarios de trabajo no agrícola & $8 \%$ & $7 \%$ & $4 \%$ & $7 \%$ \\
\hline explotación agrícola & $3 \%$ & $5 \%$ & $1 \%$ & $4 \%$ \\
\hline Transferencias & $6 \%$ & $5 \%$ & $9 \%$ & $6 \%$ \\
\hline Otros & $4 \%$ & $8 \%$ & $4 \%$ & $6 \%$ \\
\hline Total no agricultura & $21 \%$ & $25 \%$ & $19 \%$ & $23 \%$ \\
\hline
\end{tabular}

Fuente: Melo y López de Lérida (2006) en base al pareo de los encuestados en el Censo Agropecuario de 1997 con los entrevistados en las encuestas Casen de 1996 y 1998. Los promedios de ingreso no agrícola provienen del pareo de los hogares de la encuesta Casen con los del Censo Agropecuario. El desglose de las fuentes de ingresos agrícolas por cosecha/cultivo incluye todas las explotaciones agrícolas de la categoría específica en el Censo Agropecuario. 
productos importables (granos y lácteos) representan el 60\%. Los bienes no transables de todos tipos representan el 59\% de todos los gastos. Probablemente esto ha cambiado desde 1997 y la proporción de bienes transables sea mucho más alta. De las proporciones de estos gastos y del alto porcentaje de bienes transables se puede inferir que el impacto de una aceleración o desaceleración de la producción agrícola doméstica tendría un efecto limitado en los precios nominales de los alimentos para estos grupos. A la inversa, el aumento en el precio mundial de los commodities durante 2007 hasta julio de 2008 o la devaluación de la tasa de cambio desde septiembre de 2008 tendería a tener repercusiones considerablemente mayores ${ }^{4}$. El impacto de los mayores precios a nivel mundial de la leche en polvo, trigo, maíz y algunos otros productos alimentarios en los últimos meses se tradujo en un aumento significativo del componente alimentario del índice de precios al consumidor (IPC) en Chile.

\section{Una breve revisión de los usuarios de INDAP}

Un estudio de 2005 de RIMISP (Centro Latinoamericano para el Desarrollo Rural) sobre el acceso a créditos otorgados por INDAP encuestó a 1.305 usuarios y a 736 personas de un grupo de control. Hay que tener presente que los usuarios de INDAP son un subsector de los grupos de subsistencia, transición y consolidados establecidos por Melo y López de Lérida. Una estimación reciente de los pequeños productores que son usuarios de INDAP arroja un número de 45.000 (aunque entre 2000 y 2004 INDAP dio servicios a aproximadamente 90.000 personas diferentes). Los usuarios de INDAP son jefes de hogares agrícolas, principalmente hombres, que adquieren crédito para la producción, con 5 a 7 años de escolaridad y con una edad promedio ligeramente sobre los cincuenta. En promedio, los usuarios de INDAP tienen explotaciones agrícolas de 15 hectáreas, de las cuales el 19\% son regadas todo el año, y 9 de las 15 hectáreas son propiedad de ellos y el resto son bienes comunes, o aparcerías o arrendadas en efectivo. Aquellos con créditos pendientes tienen predios más grandes, y aquellos en mora tienen explotaciones agrícolas más pequeñas (7,5 hectáreas, de las cuales son dueños del 50\%). Aquellos con créditos INDAP están concentrados en la producción de trigo, papas, cebada, porotos y maíz, el 58\% tiene algún ganado y el 11\% produce fruta. Para la familia como un todo, el ingreso agrícola representa aproximadamente el 63\% del ingreso

\footnotetext{
${ }^{4}$ Véase Foster, W. y A. Valdés: "Impact of High World Commodity Prices on Real Household Income of Small Farmers: Case Study for Chile”, 2008.
} 
total de los usuarios de INDAP con créditos pendientes, y un poco menos en el caso de otros usuarios. (Véase Tabla No 36 de RIMISP.) Para los que no son usuarios en el grupo de control, el ingreso de la explotación agrícola representa solamente el 50\% del ingreso total. Los usuarios de INDAP obtienen en promedio un ingreso fuera de la explotación agrícola que representa el 25\% del total del ingreso del hogar; y curiosamente, el grupo de control fuera del INDAP obtiene menos ingresos agrícolas y menos ingresos del trabajo. En términos generales, INDAP atrae a usuarios con mayor potencial de generar ingresos.

\section{La fuerza de trabajo agrícola en base a la encuesta Casen 2003}

El lector debe tener presente, debido a las peculiaridades de lo que se entiende en Chile por "rural” y "no rural”, que casi la mitad de los trabajadores asalariados en la agricultura — muchos de los cuales viven en pequeños asentamientos - son clasificados como "urbanos”. Es más, casi un cuarto de los trabajadores independientes en la agricultura se clasifican como "urbanos". Éste es un aviso para que los analistas de los mercados laborales rurales y agrícolas tengan cuidado con las estadísticas basadas en la taxonomía oficial rural-urbano. Pero también señala la importancia de las inversiones en infraestructura realizadas en el pasado — principalmente caminos - que permiten a los trabajadores viajar todos los días hacia y desde pueblos pequeños, con gran beneficio para las familias en términos del acceso a la educación y servicios de salud.

a) ¿Quién trabaja en la agricultura chilena y cuántas familias dependen del ingreso agrícola?

Un perfil gráfico de la fuerza de trabajo y de las familias agrícolas se presenta en la Gráfico No 1 . Hacia la época de la encuesta Casen 2003, y usando los factores de expansión de población de Mideplan ${ }^{5}$, había aproximadamente 800.000 personas empleadas en la agricultura, o poco más del $13 \%$ de la fuerza de trabajo. De aquellos que se declaran como independientes o trabajadores asalariados en la agricultura, 417.074 son jefes de hogar

${ }^{5}$ La encuesta Casen 2003 entrevistó 68.153 hogares con 257.077 miembros, representando 4.130.404 hogares de 15.639.785 personas que residen en el país. El Censo de Población de 2002 fue usado para calcular factores de expansión en orden a transferir los números de las familias de la muestra que caían en distintas categorías de interés a números totales en la población del país. 
GRÁFICO N ${ }^{\circ}$ 1: $\quad$ PERFIL DE LAS FUENTES DE TRABAJO AGRÍCOLA Y HOGARES AGRÍCOLAS (encuesta Casen 2003)

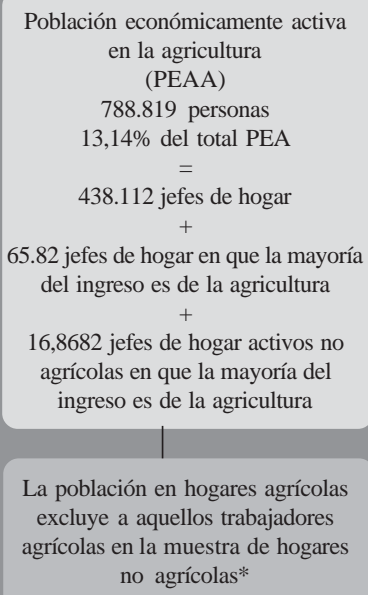

La población en hogares agrícolas excluye a aquellos trabajadores agrícolas en la muestra de hogares no agrícolas*

* Incluye hogares donde el jefe de hogar $(\mathrm{JH})$ realiza una actividad no agrícola (72.779) o el JH es inactivo (36.584).

** El jefe de hogar se declara independiente, asalariado o empleador en agricultura o, en los casos en que el JH es inactivo o inactivo en otro sector, el principal receptor de ingresos agrícolas es independiente, asalariado o empleador y al menos el 50\% del ingreso familiar autónomo proviene de la agricultura.

Fuente: Elaboración de los autores en base a encuesta Casen 2003.

(JH), 175.515 son miembros de la familia en que el JH está empleado en la agricultura y 109.363 son miembros de la familia en que el JH (cuando está activo) no está empleado en la agricultura sino en alguna otra actividad. Los trabajadores agrícolas asalariados (jefes de hogar y otros miembros de la familia) ascienden a 545.614 personas, los trabajadores agrícolas independientes a 199.053, y los empleadores a 24.979 (el remanente son familiares no pagados y trabajadores domésticos). Los lectores deben tener presente que el cuestionario Casen distingue entre el trabajador independiente y el patrón/empleador. Esto se hace, en parte, debido a una distinción legal, pues los empleadores son responsables legalmente de los contratos y las cotizaciones previsionales. Hay también una relación entre ser independiente y el tamaño de la finca en términos del número de trabajadores del estableci- 
miento al cual está asociado el encuestado. Mientras los empleadores pueden tener menos de cinco trabajadores, los independientes no aparecen asociados a faenas en que trabajen más de cinco individuos. Nótese que el número absoluto de hijos e hijas es importante: 36.448 en el caso de los independientes y 146.551 en el caso de los trabajadores asalariados. También los cónyuges (principalmente las esposas) representan una parte importante (64.311) en el caso de los trabajadores asalariados. De los independientes, el 58\% se encuentra en la zona sur del país (115.739). De los trabajadores asalariados, 58\% se encuentra en la zona central (315.057). El número de empleadores es prácticamente igual en la zona central y en la zona sur, y es pequeño en el Norte. En la zona central los predios son relativamente más grandes y dependen de mano de obra contratada, aunque el trabajo asalariado en el Sur es significativo en números absolutos (173.534).

\section{b) El objetivo del análisis: explotaciones agrícolas pequeñas y trabajadores agrícolas asalariados}

Definir los hogares agrícolas a partir de la encuesta Casen no es un asunto simple. Comenzamos contando hogares agrícolas en los cuales el jefe de hogar declara que él o ella es independiente, asalariado o un empleador en agricultura. Pero hay muchos hogares en que el jefe de hogar oficial es declarado inactivo en la fuerza de trabajo, y la suma de los ingresos de otros miembros del hogar asciende al menos al 50\% del total del ingreso familiar autónomo. Hay un número sorprendente de hogares (aproximadamente 66.000) donde el jefe de hogar oficial es inactivo, pero donde el ingreso familiar principal proviene de la agricultura. Esto podría ocurrir cuando el JH oficial está jubilado o incapacitado, y otros miembros de la familia, más jóvenes o no, están operando la explotación agrícola o son trabajadores asalariados en el sector agrícola. Aún más, hay un número menor de hogares, pero incluso así significativo, en que el jefe es activo en otro sector, pero donde nuevamente las fuentes de ingreso agrícolas de otros miembros constituyen el 50\% o más del ingreso total autónomo del hogar. En total, hay aproximadamente 17.000 hogares de este tipo.

Sumando estos tres grupos (jefe declara trabajar en agricultura, jefe inactivo pero dependiente de la agricultura y jefe activo en un sector distinto de la agricultura pero dependiente de la agricultura) da un número total de 520.822 hogares agrícolas. Quisimos separar los hogares en tres categorías: familias de trabajadores asalariados, familias agrícolas independientes y familias agrícolas de patrones/empleadores. Para aquellos hogares cuyo 
jefe oficial no es activo en la agricultura, clasificamos a la familia de acuerdo con su actividad declarada. En el caso de aquellos hogares cuyos jefes oficiales no son activos en la agricultura, los clasificamos de acuerdo con la actividad declarada del principal perceptor de ingreso agrícola. Por ejemplo, se considera que el ingreso de un hogar proviene principalmente de la agricultura, aun cuando el jefe de hogar es jubilado y obtiene quizá un ingreso no laboral, si sus hijos e hijas se ganan la vida en la agricultura. Si uno de los hijos es un trabajador agrícola asalariado que gana más de la agricultura que sus hermanos, clasificaríamos este hogar como una familia de trabajador asalariado en agricultura. Si la hija es una trabajadora agrícola independiente cuyo ingreso es el mayor de todos, entonces clasificaríamos dicho hogar como una familia agrícola independiente.

Si definimos a los hogares agrícolas de esta manera, ¿qué dicen los números? De las 520.822 familias, 30\% son independientes, 66\% son salariadas y $4 \%$ son empleadores. Esto es, en dos tercios de los hogares agrícolas el jefe de hogar o principal perceptor de ingreso agrícola es un trabajador asalariado (esta persona es considerada JH). También debiera advertirse que cerca del 15\% de la fuerza de trabajo agrícola (109.363 personas) proviene de familias donde el jefe de hogar no está en la agricultura. Estas 520 mil familias en 2003, si se expanden para incluir a los niños, mayores y otros trabajadores, representan ligeramente más de 2,1 millones de personas.

Del cuestionario Casen, y aunque arbitrario de algún modo, los trabajadores agrícolas independientes pueden ser clasificados según si operan una empresa unipersonal o si su operación tiene 5 trabajadores o menos. Dichos hogares totalizan 148.912, de los cuales el tamaño de la explotación agrícola está disponible para 151.889 explotaciones agrícolas familiares; este número de operaciones agrícolas se traduce en una población de 612.113 miembros de familia. Dos tercios de estos hogares agrícolas familiares corresponden a operaciones unipersonales (101.226), definido así por el hogar encuestado, y representan 394.781 miembros de familia (que pueden estar activos fuera de la explotación agrícola o ser dependientes). Este grupo no emplea a miembros de la familia en forma permanente, aunque algunos de ellos pueden trabajar ocasionalmente en la explotación agrícola o en otras explotaciones agrícolas, y puede tener otras fuentes de ingreso. Este grupo también podría emplear trabajadores temporales, pero no son considerados formalmente empleadores. El tercio remanente (50.663) de los hogares agrícolas son independientes, pero asociados con operaciones de dos a cinco trabajadores, y en este caso los miembros de la familia pueden ser trabajadores de largo plazo (algunos posiblemente no remunerados). Los miembros de estos hogares ascienden a 216.331 personas. 
De las 21.842 familias agrícolas que son patrones/empleadores, podemos distinguir dos tipos: aquellas con cinco o menos empleados (13.041 hogares) y aquellas con más de cinco empleados (8.801 hogares). ¿Debiéramos tratar el grupo patrón/empleador con dos a cinco empleados como familias agrícolas similares a las independientes? Como veremos a continuación, la distribución de ingresos de las familias patrones/empleadores es muy diferente de la de familias independientes y, de hecho, similar a la de aquellas familias patrones/empleadores con más de cinco empleados.

En breve, por agricultura de explotación agrícola familiar nos estamos refiriendo a aproximadamente 150 mil hogares que comprenden a aproximadamente 600 mil personas. Cerca de 50 mil de estas explotaciones agrícolas familiares corresponden también a empleadores de pequeña escala, que tienen entre dos y cinco trabajadores. Es posible anticipar que el grupo relativamente más pobre dentro de la agricultura de explotación agrícola familiar estará concentrado dentro de los aproximadamente cien mil hogares con operaciones unipersonales (esto es, sin trabajadores permanentes).

c) ¿En empresas de qué tamaño trabajan los trabajadores asalariados?

Como lo muestra la Tabla $\mathrm{N}^{\circ}$ 6, la agricultura en Chile tiene una alta proporción de la fuerza de trabajo total del sector trabajando en empresas comerciales de diez o más trabajadores. Para el país como un todo, el 56\% de la fuerza de trabajo no agrícola trabaja en dichas empresas, comparado con el 51\% de la fuerza de trabajo agrícola. Mientras que el porcentaje de la fuerza de trabajo no agrícola en estas empresas permanece relativamente estable geográficamente, el porcentaje de la fuerza de trabajo agrícola es más sensible a la región de producción. En el Norte, las empresas de diez o más trabajadores emplean el $49 \%$ de la fuerza de trabajo agrícola de la región, y en el Sur emplean el 37\%. En la zona central, que es más desarrollada, las empresas de diez o más trabajadores en el sector agrícola emplean a un porcentaje mayor de los trabajadores del sector que sus contrapartes en el sector no agrícola: $63 \%$ contra $57 \%$. Pero cabe notar que de un total de 545.864 trabajadores asalariados en la agricultura, 251.374 son trabajadores permanentes y 292.815 son empleados a corto plazo, por temporada o por labor. De todos los trabajadores temporales en todos los sectores, la agricultura ocupa al $27 \%$ de éstos (la construcción al 17\%). Así que, al menos por una parte del año, la agricultura de gran escala es el componente mayoritario de la demanda laboral del sector a nivel nacional, especialmente en la 


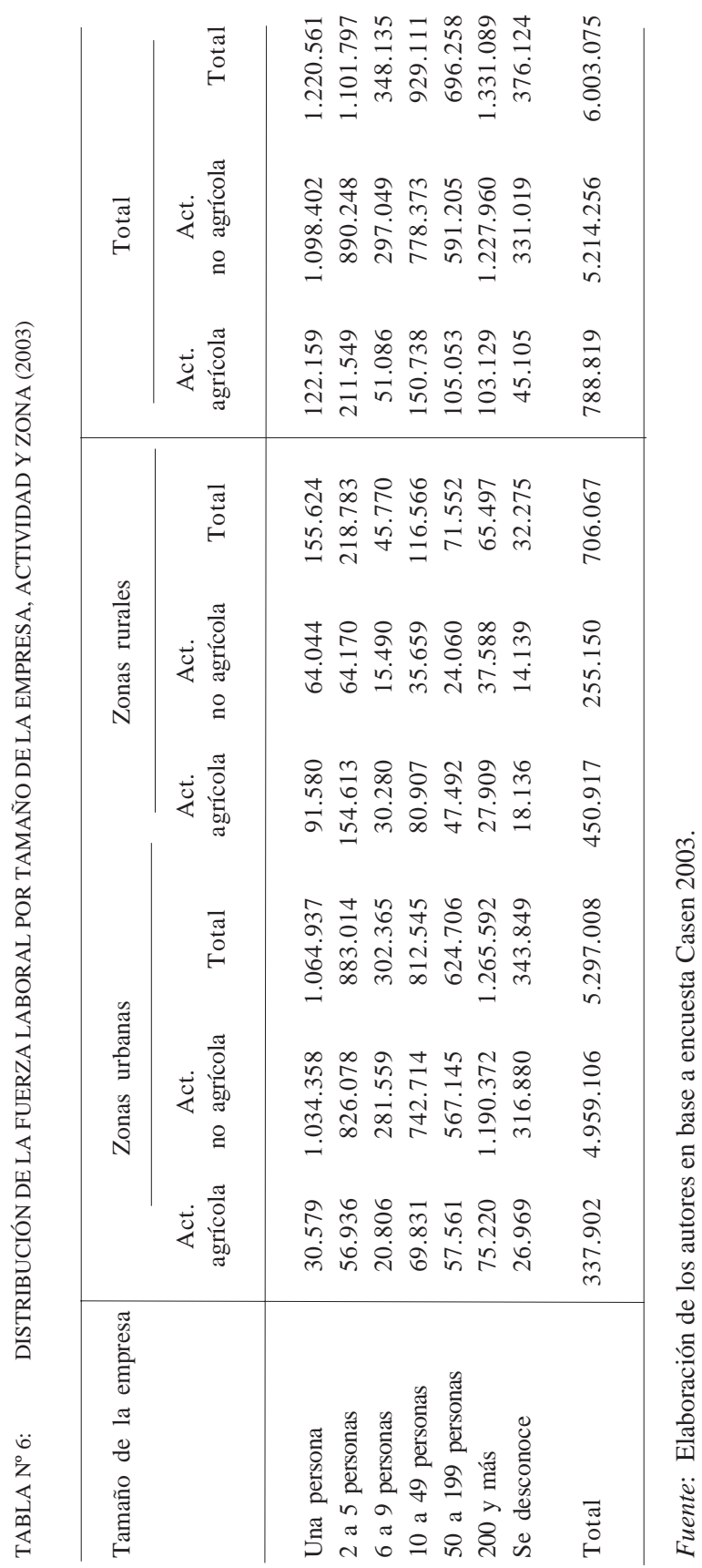


zona central, pero también constituye una parte importante en el Sur. En el otro extremo, la explotación agrícola familiar está unida a trabajadores agrícolas independientes de empresas unipersonales o con dos a cinco empleados. Dichas explotaciones agrícolas emplean a 333.700 personas, esto es, al $42 \%$ de la fuerza de trabajo agrícola.

\section{Pobreza e ingreso del hogar agrícola según la encuesta Casen 2003}

a) Pobreza entre los independientes y trabajadores asalariados en la agricultura: comparación de distribuciones de ingreso entre actividades

La población actual de Chile es de 16,5 millones de habitantes. Este análisis hace uso del Censo de Población de 2002, cuando la población era de 15,6 millones en 4,1 millones de hogares. La tasa oficial de pobreza es estimada por Mideplan en poco menos de 19\%, y ha disminuido substancialmente desde 1987 (fecha de la primera encuesta Casen). Como lo muestra la Tabla $\mathrm{N}^{\circ} 7$, hay más familias en pobreza o situación de vulnerabilidad entre los trabajadores asalariados que el promedio nacional, y también que entre los trabajadores agrícolas independientes dueños de explotaciones agrícolas pequeñas. Pero los lectores debieran notar que la distribución de ingreso entre los trabajadores independientes (por cuenta propia) es mucho más dispersa (y la media desplazada hacia arriba) que entre los trabajadores asalariados, tanto en la agricultura como fuera de ella, como lo indican las Gráficos $\mathrm{N}^{\mathrm{os}}$ 2a, 2b y 3. De hecho, es preciso advertir al lector que las estadísticas que muestran ingresos promedio y características de grupos, especialmente en el caso de los independientes, presentan una dispersión del ingreso muy amplia en esta categoría, e incluyen hogares con ingresos altos que caerían fuera de lo que sería considerado el grupo de explotaciones agrícolas familiares respecto de las cuales debieran ocuparse las políticas. Los independientes están recibiendo ingresos tanto del trabajo como por retornos del capital propio (incluyendo quizás su capital humano, a veces específico de la explotación agrícola) y administración. Y en el núcleo familiar, el jefe de hogar y/o sus familiares pueden permanecer en el trabajo agrícola incluso si su ingreso por su trabajo es inferior a su costo de oportunidad (como asalariado), porque reciben un ingreso medio que no distingue entre los retornos del capital propio y su contribución como mano de obra. Las distribuciones de ingreso de patrones/empleadores están desplazadas a la derecha en comparación con las de los independientes. Claramente, la familia agrícola independiente (agricultura familiar) es un grupo diferente de la familia agrícola de patrón/empleador con dos a cinco trabajadores. 
TABLA N ${ }^{\circ}$ 7: $\quad$ PERFIL DE POBREZA DE HOGARES AGRÍCOLAS CHILENOS (jefe de hogar, JH) SEGÚN SITUACIÓN LABORAL (encuesta Casen 2003)

\begin{tabular}{|c|c|c|c|c|c|}
\hline Situación de trabajo & $\begin{array}{c}\text { Extremadamente } \\
\text { pobre } \\
\text { (indigente) }\end{array}$ & $\begin{array}{c}\text { Pobre } \\
\text { no } \\
\text { indigente }\end{array}$ & $\begin{array}{c}\text { Vulnerable } \\
\text { (ingreso entre } \\
1 \text { y } 1,5 \text { veces } \\
\text { bajo la línea } \\
\text { de pobreza) }\end{array}$ & $\begin{array}{l}\text { No pobre } \\
\text { ni vulnerable }\end{array}$ & Total \\
\hline JH independiente & 6.421 & 14.802 & 20.980 & 111.199 & 153.402 \\
\hline JH trabajador asalariado & 16.573 & 66.173 & 77.390 & 184.869 & 345.005 \\
\hline JH empleador & 220 & 381 & 348 & 21.466 & 22.415 \\
\hline Total & 23.214 & 81.356 & 98.718 & 317.534 & 520.822 \\
\hline JH independiente & $4 \%$ & $10 \%$ & $14 \%$ & $72 \%$ & $100 \%$ \\
\hline JH trabajador asalariado & $5 \%$ & $19 \%$ & $22 \%$ & $54 \%$ & $100 \%$ \\
\hline JH empleador & $1 \%$ & $2 \%$ & $2 \%$ & $96 \%$ & $100 \%$ \\
\hline Total & $4 \%$ & $16 \%$ & $19 \%$ & $61 \%$ & $100 \%$ \\
\hline \multicolumn{6}{|l|}{$\begin{array}{l}\text { Para comparación: } \\
\text { JH trabajador asalariado } \\
\text { no agrícola }\end{array}$} \\
\hline \multirow{2}{*}{$\begin{array}{l}\text { Número de hogares } \\
\text { Porcentaje de todos los JH } \\
\text { asalariados no agrícola }\end{array}$} & 31.869 & 203.719 & 273.483 & 1.231 .971 & 1.741 .042 \\
\hline & $1,8 \%$ & $11,7 \%$ & $15,7 \%$ & $70,8 \%$ & $100 \%$ \\
\hline JH independiente & $27,7 \%$ & $18,2 \%$ & $21,3 \%$ & $35,0 \%$ & $29,5 \%$ \\
\hline JH trabajador asalariado & $71,4 \%$ & $81,3 \%$ & $78,4 \%$ & $58,2 \%$ & $66,2 \%$ \\
\hline JH empleador & $0,9 \%$ & $0,5 \%$ & $0,4 \%$ & $6,8 \%$ & $4,3 \%$ \\
\hline Total & $100 \%$ & $100 \%$ & $100 \%$ & $100 \%$ & $100 \%$ \\
\hline
\end{tabular}

Nota: Estimaciones para independientes, trabajadores asalariados y empleadores incluyen hogares donde el jefe de familia es inactivo pero el ingreso agrícola constituye más del $50 \%$ del ingreso autónomo del hogar. Indigencia es definida como un ingreso suficiente para cubrir el costo de una canasta alimentaria básica. La línea de pobreza corresponde al doble del costo de esa canasta básica. Vulnerabilidad es definida aquí como una situación por sobre la línea de pobreza, pero con un ingreso 1,5 veces bajo la línea de pobreza.

Fuente: Elaboración de los autores a partir de la encuesta Casen 2003.

Si bien hay muchos hogares dueños de pequeñas explotaciones agrícolas en los cuales hay miembros de la familia empleados en actividades no agrícolas, la proporción de pequeñas explotaciones agrícolas que obtienen menos del 50\% de su ingreso total autónomo del hogar de la agricultura alcanza aproximadamente al 10\% — y esta proporción es similar a la proporción de hogares cuyo jefe es un trabajador agrícola asalariado que obtiene 
GRÁFICO No 2a: DISTRIBUCIÓN DE INGRESO DE LA FUENTE DE TRABAJO AGRÍCOLA POR SITUACIÓN LABORAL

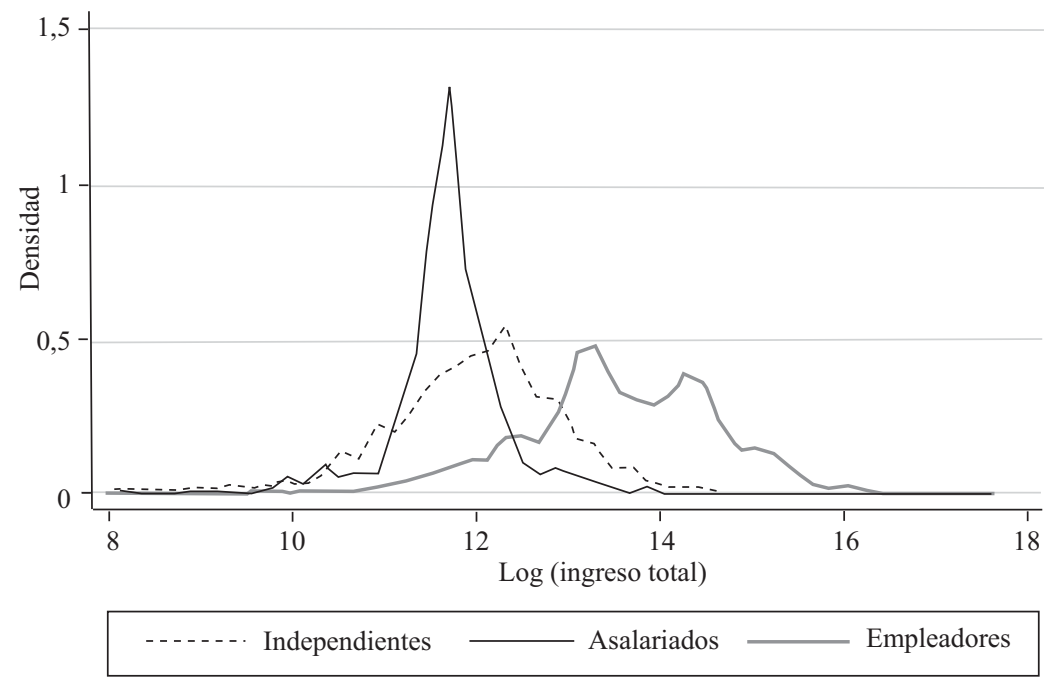

Fuente: Elaboración de los autores a partir de la encuesta Casen 2003.

GRÁFICO No 2b: DISTRIBUCIÓN DEL INGRESO DE LOS TRABAJADORES AGRÍCOLAS SEGÚN SITUACIÓN LABORAL Y TAMAÑO DE LA EMPRESA

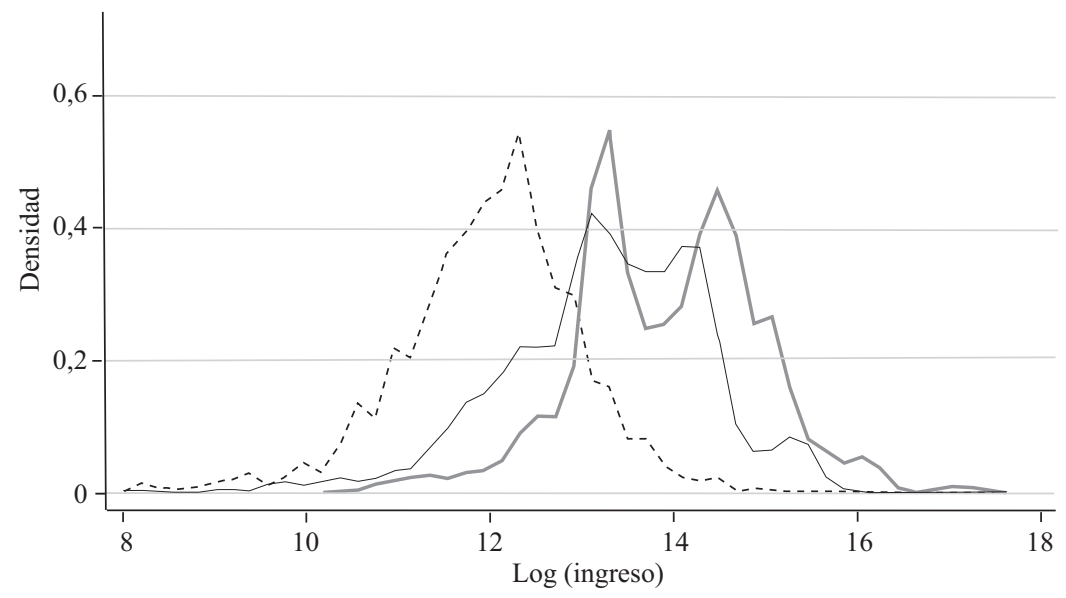

Independientes

Empleadores con -5

Empleadores con +5

Fuente: Encuesta Casen 2003. 
GRÁFICO N 3: DISTRIBUCIÓN DEL INGRESO DE LA FUERZA DE TRABAJO NO AGRÍCOLA SEGÚN SITUACIÓN LABORAL

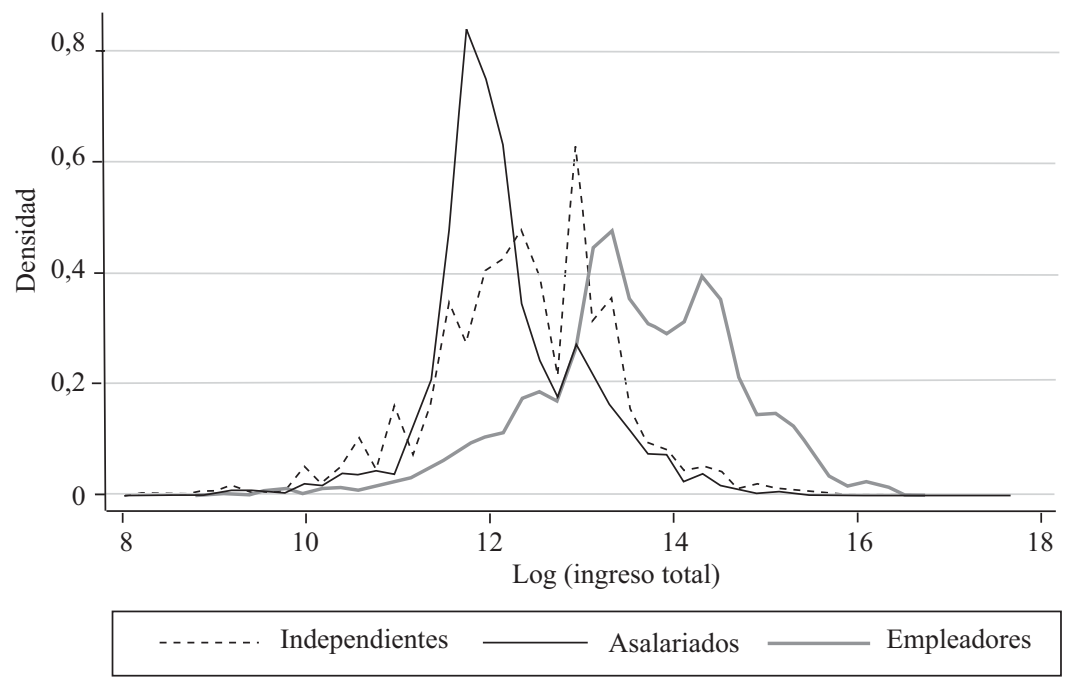

Fuente: Elaboración de los autores a partir de la encuesta Casen 2003.

menos del 50\% de sus ingresos de la agricultura. Esto es, el grueso del ingreso para ambos grupos está concentrado, en promedio, fuertemente en la agricultura. Pero en el caso de los independientes el ingreso proviene de una gran variedad de fuentes. Es sorprendente la alta incidencia de pobreza y vulnerabilidad entre los trabajadores agrícolas asalariados. En comparación con los trabajadores asalariados en sectores no agrícolas, los ingresos de los trabajadores agrícolas asalariados son muy inferiores. El perfil de pobreza de los pequeños propietarios agrícolas es similar al de los trabajadores asalariados no agrícolas, si no ligeramente peor.

Si uno de los objetivos de la política social es abocarse a los extremadamente pobres en la agricultura, hay 16.000 familias chilenas extremadamente pobres entre los trabajadores asalariados agrícolas y 6.000 entre los independientes. Asimismo, hay 66.000 familias de trabajadores agrícolas asalariados pobres, y 14.000 familias adicionales de los independientes. Y considerando todas las familias de trabajadores asalariados, que son más del doble del número total de familias en el caso de los independientes, el $46 \%$ de ellas pueden ser clasificadas como vulnerables o pobres.

Pero una comparación relevante entre trabajadores asalariados y "familias agrícolas” es realmente entre trabajadores asalariados y familias agrí- 
colas que dependen de la agricultura, porque la más alta dispersión del ingreso de los pequeños trabajadores agrícolas dueños de sus explotaciones agrícolas generalmente podría ser el resultado del ingreso obtenido fuera de la agricultura. Uno podría esperar que los trabajadores asalariados, especialmente aquellos que viven en áreas urbanas (alrededor del 50\%), serían más móviles que los pequeños propietarios agrícolas cualquiera sea la fuente de su ingreso adicional. Pero esto aparece no ser consistente con el perfil de pobreza. Al examinar en mayor detalle el perfil de pobreza entre los trabajadores agrícolas independientes, se puede apreciar que la mayor dispersión y más alta media de ingresos entre ellos (véase el Gráfico Nº 2a) parece obedecer principalmente a que dependen de fuentes no agrícolas.

El perfil de pobreza de aquellas familias agrícolas que dependen exclusivamente de la agricultura es muy similar a aquel de los trabajadores agrícolas asalariados, como se ve en la Tabla $\mathrm{N}^{\circ}$ 8. De hecho, la tasa de indigencia entre familias de explotaciones agrícolas unipersonales que dependen exclusivamente del ingreso agrícola es casi el doble que la de los trabajadores agrícolas asalariados (8,3\% contra 4,9\%), aunque los porcentajes de pobres/no-indigentes y vulnerables son levemente menores (14,3\% contra 19,3\%, y 18,6\% contra 22,4\%). Y los hogares que dependen exclusiCIÓN AGRÍCOLA, FUENTE DE INGRESO Y PERFIL DE POBREZA (2003) (\%)

\begin{tabular}{|c|c|c|c|c|c|c|c|}
\hline & \multicolumn{3}{|c|}{$\begin{array}{l}\text { Explotaciones agrícolas } \\
\text { unipersonales }\end{array}$} & \multicolumn{2}{|c|}{$\begin{array}{c}\text { Explotaciones } \\
\text { agrícolas de } 2 \\
\text { a } 5 \text { personas }\end{array}$} & \multicolumn{2}{|c|}{$\begin{array}{c}\text { Todas las } \\
\text { explotaciones } \\
\text { agrícolas }\end{array}$} \\
\hline & $\begin{array}{c}\text { Sólo } \\
\text { ingreso } \\
\text { agrícola }\end{array}$ & $\begin{array}{c}\text { Ingreso } \\
\text { agrícola } \\
<50 \% \\
\text { del } \\
\text { ingreso } \\
\text { total }\end{array}$ & $\begin{array}{c}\text { Ingreso } \\
\text { agrícola } \\
\geq 50 \% \\
\text { del } \\
\text { ingreso } \\
\text { total }\end{array}$ & $\begin{array}{c}\text { Ingreso } \\
\text { agrícola } \\
<50 \% \\
\text { del } \\
\text { ingreso } \\
\text { total }\end{array}$ & $\begin{array}{c}\text { Ingreso } \\
\text { agrícola } \\
\geq 50 \% \\
\text { del } \\
\text { ingreso } \\
\text { total }\end{array}$ & $\begin{array}{c}\text { Ingreso } \\
\text { agrícola } \\
<50 \% \\
\text { del } \\
\text { ingreso } \\
\text { total }\end{array}$ & $\begin{array}{c}\text { Ingreso } \\
\text { agrícola } \\
\geq 50 \% \\
\text { del } \\
\text { ingreso } \\
\text { total }\end{array}$ \\
\hline Extremadamente pobres (indigentes) & 8,3 & 1,4 & 4,8 & 8,8 & 2,8 & 3,4 & 4,1 \\
\hline Pobre & 14,3 & 5,5 & 9,8 & 8,7 & 10,5 & 6,4 & 10,0 \\
\hline $\begin{array}{l}\text { No pobre bajo } 1,5 \text { veces la línea } \\
\text { de pobreza } \\
\text { No pobre ni vulnerable }\end{array}$ & $\begin{array}{l}18,6 \\
58,7\end{array}$ & $\begin{array}{l}12,6 \\
80,5\end{array}$ & $\begin{array}{l}14,3 \\
71,0\end{array}$ & $\begin{array}{r}8,6 \\
73,9\end{array}$ & $\begin{array}{l}13,4 \\
73,2\end{array}$ & $\begin{array}{l}11,5 \\
78,7\end{array}$ & $\begin{array}{l}14,0 \\
71,8\end{array}$ \\
\hline Total & 100,00 & 100,00 & 100,00 & 100,00 & 100,00 & 100,00 & 100,00 \\
\hline
\end{tabular}

Nota: Estimaciones incluyen hogares donde el jefe de hogar es inactivo pero el ingreso agrícola constituye más del 50\% del ingreso autónomo del hogar.

Fuente: Elaboración de los autores a partir de la encuesta Casen 2003. 
vamente del ingreso agrícola asociado a explotaciones agrícolas con empleo a pequeña escala muestran un perfil de pobreza muy similar al de los trabajadores agrícolas asalariados. Evidentemente entonces, al menos al usar cifras nacionales, el hecho de ser sólo un trabajador agrícola no reduce la probabilidad de ser pobre. Atributos familiares que llevan a mejores ingresos, quizás tanto agrícolas como no agrícolas, son factores importantes, los cuales exploramos a continuación.

\section{b) Estimación de ecuaciones de ingreso: relación de características regionales y familiares con ingreso per cápita del hogar}

En esta sección analizamos los determinantes del ingreso autónomo de hogares agrícolas donde el jefe de hogar (independiente o asalariado) se declara a sí mismo en la agricultura, o donde el JH es inactivo o es activo en otros sectores, pero la agricultura constituye al menos el 50\% del ingreso autónomo total. (Como se indicó en la sección 4 precedente, al clasificar hogares como "pequeños propietarios agrícolas" o "trabajadores asalariados” donde el jefe no es activo en la agricultura, usamos la actividad del principal perceptor de ingreso activo en la agricultura.) De un total de más de 60.000 hogares encuestados, la base de datos de la encuesta Casen 2003 contiene 17.963 observaciones de hogares agrícolas de acuerdo con nuestra definición: 7.190 familias agrícolas y 10.773 familias de trabajadores asalaria$\operatorname{dos}^{6}$. Se pueden identificar determinantes del ingreso del hogar usando ecuaciones de ingreso que permiten estimar el efecto parcial de varias variables relevantes. En nuestro caso queremos explicar los determinantes del ingreso per cápita del hogar (expresado como adulto equivalente) y examinar en qué grado se pueden distinguir los impactos marginales de los determinantes identificados entre familias agrícolas y de trabajadores asalariados.

Definimos ingreso como el ingreso familiar autónomo que proviene de todas las distintas fuentes y que es generado por todos los miembros de

${ }^{6}$ En las siguientes regresiones las observaciones son ponderadas por los factores de expansión utilizados por Mideplan en base al Censo de Población de 2002; a su vez, son una corrección posterior de la muestra estocástica para reflejar las desviaciones de la población en la muestra debido a la naturaleza aleatoria de la encuesta. Las ponderaciones de la población recentran la distribución de la muestra alrededor de lo que se conoce de la población del Censo con respecto a las características demográficas. La información de la encuesta Casen viene en forma de muestra, pero cada observación tiene un factor de expansión proporcionado por Mideplan, que es en términos del número de hogares que la observación de la muestra representa de la población total. Los resultados de la regresión sin ponderaciones de población son muy similares a los reportados aquí. 
la familia. Incluimos remesas de dinero, pero excluimos subsidios en efectivo gubernamentales y cualquier monto que pudiera imputarse como renta de la vivienda propia. El ingreso per cápita del adulto equivalente se basa en el esquema de peso de la edad de los miembros de la familia desarrollado por Rothbarth conforme con la escala del Banco Mundial ${ }^{7}$. Este análisis se basa en una ecuación de regresión simple que relaciona ingreso con características del hogar y que incluye las siguientes variables independientes: edad del jefe de hogar (JH), escolaridad del JH, género del JH, etnicidad del JH, proporción de dependencia de la familia, tamaño de la familia, número de miembros en edad de trabajar, dependencia de la producción agrícola en el ingreso total, residencia rural o urbana, sector declarado de actividad principal del JH, tamaño de la explotación agrícola (si es relevante), empleo permanente o no, y efectos regionales.

Edad y escolaridad se miden en años. Etnicidad es una variable dicotómica, igual a 1 si el jefe de hogar se declara a sí mismo como miembro de un grupo indígena, y 0 en cualquier otro caso. Género también es dicotómico: igual a 1 si el JH se declara a sí mismo hombre, 0 en cualquier otro caso. La proporción de dependencia es el número de miembros del hogar relativo al número de miembros económicamente activos, y tamaño de la familia es el simple conteo del número de personas en el hogar. El número de personas en edad de trabajar es el simple conteo de personas mayores de catorce años. Dependencia de fuentes de ingreso agrícola es indicada por dos variables dicotómicas. La primera es 1 si todo el ingreso autónomo deriva de producción agrícola o trabajo agrícola, e igual a 0 en cualquier otro caso. El segundo, aplicable sólo a familias cuyo jefe de hogar se declara a sí mismo en la agricultura, es igual a 1 si el ingreso agrícola es mayor que el 50\%, y 0 en cualquier otro caso. Residencia urbana-rural es indicada por un valor dicotómico, igual a 1 si el hogar se encuentra en una zona definida oficialmente como zona urbana, y 0 en cualquier otro caso (esto es, viviendo en una zona rural). Aun cuando estamos examinando ingreso de hogares que se declaran a sí mismos en la agricultura o donde la mayoría de sus ingresos deriva de la agricultura o del trabajo agrícola, también incluimos variables dicotómicas para indicar si el jefe de hogar se declara a sí mismo activo en un sector no agrícola (igual a 1 , e igual a 0 en cualquier otro caso), y si se declara inactivo (igual a 1, y 0 en cualquier otro caso). El tamaño de la

\footnotetext{
${ }^{7}$ Véase World Bank: "Chile: Poverty and Income Distribution in a High Growth Economy”, 1997, Anexo 1, p. 7. La Escala de Rothbarth para un hogar de una persona es la siguiente: jefes de hogar tienen un peso de 1,2; por cada adulto y niño adicional entre 11 y 15 años el peso es de 0,8; niños entre 5 y 10 años de edad tienen un peso de 0,4, y niños menores de 5 años tienen un peso de 0,3 .
} 
explotación agrícola es indicado por una variable que señala si el trabajador agrícola declara trabajar en una operación unipersonal (valor igual a 1, y 0 en cualquier otro caso). Para jefes de hogar asalariados, una variable dicotómica también indica empleo permanente (igual a 1, y 0 en cualquier otro caso). Finalmente, los efectos regionales también son variables dummy, y elegimos la Región Metropolitana como la referencia.

Hemos visto anteriormente, en la discusión de la información agregada de la Tabla $\mathrm{N}^{\mathrm{o}} 7$, que hay por cierto grandes diferencias de ingreso entre los trabajadores asalariados y los independientes, y diferencias de acuerdo con la dependencia del ingreso agrícola. Quizás estas diferencias son explicadas por variaciones respecto a los determinantes de ingreso (y respuestas de ingreso a esos determinantes) entre los dos grupos. Por lo tanto, tomamos en cuenta posibles diferencias realizando regresiones que separan los dos grupos y permiten a las variables tener efectos diferentes. Los resultados de la regresión para la ecuación de ingreso simple precedente aparecen en las Tablas $\mathrm{N}^{\text {os }}$ 9, 10 y 11. La Tabla $\mathrm{N}^{\circ} 10$ muestra una regresión que combina hogares de trabajadores agrícolas asalariados y hogares de pequeños propietarios, lo que es equivalente a suponer que el término de error tiene la misma variancia para las dos subpoblaciones. Para relajar este supuesto, las Tablas $\mathrm{N}^{\mathrm{os}} 10$ y 11 reportan dos regresiones separadas para los dos grupos, aunque los efectos marginales estimados de las variables explicativas en las regresiones separadas son muy cercanos a aquellos implicados en la regresión que combina a los dos grupos. La regresión única de la Tabla $N^{\circ} 9$ es estimada usando una variable dummy que representa un hogar agrícola independiente que interactúa con los otros determinantes de ingreso. Los coeficientes de estas variables son interpretados como efectos en el margen (en logaritmo de ingreso) de los determinantes en comparación con el grupo de referencia, que es el hogar del trabajador asalariado.

En el caso de la edad, ambos grupos muestran un ingreso per cápita mensual del hogar que aumenta a medida que el jefe de hogar tiene más edad (para los trabajadores asalariados, después de los 17 años), pero los hogares agrícolas independientes muestran evidencia de que este crecimiento es a una tasa decreciente, alcanzando un máximo a los 55 años. Para hogares de trabajadores asalariados, el ingreso aumenta a una tasa que aumenta con la edad del JH (desde que el JH es mayor de 17 años), aunque este efecto es pequeño en una base anual (menos de medio por ciento de aumento en el ingreso por cada año adicional sobre un rango razonable de vida de trabajo). Mirando los cambios marginales de escolaridad dentro de cada grupo, cada año adicional aporta a la familia del trabajador asalariado aproximadamente 9,3\% más per cápita por mes, comparado con aproximada- 
TABLA No 9: REGRESIÓN DEL INGRESO PER CÁPITA DEL HOGAR, EQUIVALENTE A ADUL-
TO, EN PESOS DE 2003 (en logaritmos): TRABAJADORES INDEPENDIENTES Y
TRABAJADORES ASALARIADOS EN LA AGRICULTURA

\begin{tabular}{|c|c|c|c|c|c|c|}
\hline \multirow{2}{*}{$\begin{array}{l}\text { Ingreso per cápita del hogar, } \\
\text { equivalente a adulto, en } \\
\text { pesos de } 2003 \\
\text { Variables }\end{array}$} & \multicolumn{3}{|c|}{$\begin{array}{l}\text { Hogar trabajador agrícola } \\
\text { asalariado (referencia) }\end{array}$} & \multicolumn{3}{|c|}{$\begin{array}{l}\text { Hogar pequeña explotación agrícola } \\
\text { (la estimación reportada es adicional } \\
\text { a la obtenida para los asalariados) }\end{array}$} \\
\hline & Estimación & Error estándar & [t-stat $]$ & Estimación & Error estándar & [t-stat] \\
\hline Edad JH & -0.00323 & 0.00055 & -5.84 & 0.01976 & 0.00091 & 21.77 \\
\hline Edad al cuadrado & 0.00008 & 0.00001 & 12.67 & -0.00023 & 0.00001 & -23.89 \\
\hline Sin educación & 0.52551 & 0.00655 & 80.24 & -0.09189 & 0.01127 & -8.16 \\
\hline \multicolumn{7}{|l|}{$\begin{array}{l}\text { Educación, pero básica } \\
\text { incompleta }\end{array}$} \\
\hline (1 año $<x<6$ años $)$ & 0.25238 & 0.00345 & 73.12 & -0.10203 & 0.00610 & -16.72 \\
\hline Número de años de escolaridad & 0.08835 & 0.00046 & 194.02 & -0.00646 & 0.00088 & -7.36 \\
\hline Si JH hombre = 1 & 0.09904 & 0.00383 & 25.83 & 0.09468 & 0.00757 & 12.50 \\
\hline Si indígena $=1$ & -0.04753 & 0.00476 & -9.98 & -0.15549 & 0.00677 & -22.97 \\
\hline Proporción de dependencia & -0.18758 & 0.00098 & -191.23 & 0.06186 & 0.00175 & 35.34 \\
\hline Número de miembros del hogar & -0.02585 & 0.00125 & -20.76 & -0.03363 & 0.00222 & -15.15 \\
\hline $\begin{array}{l}\text { Número de miembros }>14 \\
\text { Si ingreso agrícola }>50 \% \\
\text { del total autónomo }\end{array}$ & -0.01796 & 0.00153 & -11.74 & -0.00589 & 0.00266 & -2.21 \\
\hline Variable $=1$ & -0.05004 & 0.00395 & -12.67 & 0.37223 & 0.00684 & 54.45 \\
\hline $\begin{array}{l}\text { Si ingreso agrí́cola }=100 \% \\
\text { de total autónomo }=1\end{array}$ & -0.40935 & 0.00253 & -161.98 & -0.36703 & 0.00435 & -84.43 \\
\hline Si urbano $=1$ & 0.01698 & 0.00223 & 7.62 & 0.03387 & 0.00463 & 7.32 \\
\hline Si JH declara en otro sector $=1$ & -0.15347 & 0.00543 & -28.28 & - & - & - \\
\hline Si JH declara inactivo $=1$ & -0.08039 & 0.00295 & -27.23 & - & - & - \\
\hline $\begin{array}{l}\text { Si explotación agrícola es } \\
\text { unipersonal = } 1\end{array}$ & - & - & - & -0.08329 & 0.00337 & -24.69 \\
\hline Si asalariado permanente $=1$ & 0.31560 & 0.00220 & 143.66 & - & - & - \\
\hline Constante & 11.11 & .0141003 & 788.26 & 0.12464 & 0.02631 & 4.74 \\
\hline
\end{tabular}

Efectos regionales (Región Metropolitana es la referencia):

Hogar trabajador agrícola asalariado (referencia)

\begin{tabular}{lrrr|rrr} 
& & & & & \\
\cline { 5 - 6 } dr1 & -0.08080 & 0.01098 & -7.36 & -0.19217 & 0.01637 & -11.74 \\
dr2 & -0.01324 & 0.01846 & -0.72 & 0.02447 & 0.02289 & 1.07 \\
dr3 & -0.11718 & 0.00747 & -15.70 & -0.05749 & 0.01679 & -3.42 \\
dr4 & -0.20601 & 0.00492 & -41.89 & -0.23346 & 0.01016 & -22.97 \\
dr5 & -0.13181 & 0.00426 & -30.93 & -0.17387 & 0.00987 & -17.62 \\
dr6 & -0.09308 & 0.00376 & -24.73 & 0.06002 & 0.00979 & 6.13 \\
dr7 & -0.19130 & 0.00384 & -49.87 & -0.11351 & 0.00882 & -12.86 \\
dr8 & -0.20232 & 0.00381 & -53.15 & -0.38240 & 0.00830 & -46.10 \\
dr9 & -0.20265 & 0.00511 & -39.64 & -0.17049 & 0.00941 & -18.12 \\
dr10 & -0.06844 & 0.00416 & -16.44 & -0.28620 & 0.00848 & -33.77 \\
dr11 & 0.03489 & 0.01134 & 3.08 & -0.26782 & 0.01731 & -15.47 \\
dr12 & 0.21085 & 0.01128 & 18.69 & -0.27730 & 0.02360 & -11.75 \\
\hline
\end{tabular}

$\mathrm{R}^{2}=0,4989$.

$\mathrm{F}(55,494039)=8.943,96$.

$\mathrm{N}=17.963$ (7.190 independientes, 10.773 trabajadores asalariados).

Nota: $\mathrm{JH}=$ jefe de hogar. La muestra incluye hogares en que el jefe declara en agricultura o, cuando es inactivo, la agricultura representa más del 50\% del ingreso total autónomo del hogar. En el caso de hogares en que el jefe no es activo en la agricultura, las características de $\mathrm{JH}$ son las del principal generador de ingresos agrícolas. 
TABLA N ${ }^{\circ}$ 10: REGRESIÓN DEL INGRESO PER CÁPITA DEL HOGAR, EQUIVALENTE A ADULTO, EN PESOS DE 2003 (en logaritmos): SÓLO TRABAJADORES INDEPENDIENTES EN AGRICULTURA

Ingreso per cápita del hogar equivalente a adulto en pesos de 2003

Variables

Edad JH

Edad al cuadrado

Sin educación

Educación, pero básica incompleta

(1 año $<\mathrm{x}<6$ años)

Número de años de escolaridad

Si JH hombre $=1$

Si indígena $=1$

Proporción de dependencia

Número de miembros del hogar

Número de miembros $>14$

Si ingreso agrícola $>50 \%$ del total autónomo

Variable $=1$

Si ingreso agrícola $=100 \%$ de total autónomo $=1$

Si urbano $=1$

Si $\mathrm{JH}$ declara en otro sector $=1$

Si JH declara inactivo $=1$

Si explotación agrícola unipersonal $=1$

Constante
Hogares explotación agrícola independientes

$\begin{array}{rrr}\text { Estimación } & \text { Error estándar } & \text { [t-stat] } \\ & & \\ 0.01424 & 0.00092 & 15.54 \\ -0.00013 & 0.00001 & -14.66 \\ 0.42298 & 0.01125 & 37.59 \\ & & \\ 0.14324 & 0.00618 & 23.19 \\ 0.08056 & 0.00093 & 87.00 \\ 0.18490 & 0.00817 & 22.64 \\ -0.20353 & 0.00587 & -34.69 \\ -0.12121 & 0.00180 & -67.49 \\ -0.06837 & 0.00232 & -29.44 \\ -0.01107 & 0.00284 & -3.90 \\ & & \\ 0.32525 & 0.00695 & 46.83 \\ -0.77431 & 0.00435 & -177.86 \\ 0.04466 & 0.00497 & 8.99 \\ -0.05399 & 0.01294 & -4.17 \\ -0.18924 & 0.00658 & -28.78 \\ -0.08414 & 0.00412 & -20.43 \\ 11.29889 & 0.02832 & 398.90\end{array}$

Efectos regionales (Región Metropolitana es la referencia):

Hogar explotación agrícola independiente

\begin{tabular}{lrrr}
\cline { 2 - 4 } dr1 & -0.25052 & 0.01492 & -16.79 \\
dr2 & 0.01396 & 0.01657 & 0.84 \\
dr3 & -0.15702 & 0.01843 & -8.52 \\
dr4 & -0.41364 & 0.01097 & -37.70 \\
dr5 & -0.27207 & 0.01102 & -1.68 \\
dr6 & -0.01276 & 0.01118 & -28.66 \\
dr7 & -0.28157 & 0.00982 & -61.38 \\
dr8 & -0.56082 & 0.00914 & -35.57 \\
dr9 & -0.34722 & 0.00976 & -36.17 \\
dr10 & -0.33060 & 0.00914 & -13.27 \\
dr11 & -0.21245 & 0.01601 & -1.05 \\
dr12 & -0.02667 & 0.02540 & \\
\hline
\end{tabular}

$$
\begin{aligned}
& \mathrm{R}^{2}=0,4516 . \\
& \mathrm{F}(28,152242)=4.478,45 . \\
& \mathrm{N}=7.190 \text { independientes. }
\end{aligned}
$$

Nota: $\mathrm{JH}=$ jefe de hogar. En contraste con las regresiones de las Tablas $\mathrm{N}^{\circ \mathrm{s}}$ 9, 10 y 11, la muestra incluye hogares en que el jefe es activo en otro sector y la agricultura representa más del 50\% del ingreso total autónomo del hogar. En el caso de hogares en que el jefe no es activo en la agricultura, las características de JH son las del principal generador de ingresos agrícolas. 
TABLA N ${ }^{\circ}$ 11: REGRESIÓN DEL INGRESO PER CÁPITA DEL HOGAR, EQUIVALENTE A ADULTO, EN PESOS DE 2003 (en logaritmos): SÓLO TRABAJADORES ASALARIADOS EN LA AGRICULTURA

\begin{tabular}{|c|c|c|c|}
\hline \multirow{2}{*}{$\begin{array}{l}\text { Ingreso per cápita del hogar equivalente } \\
\text { a adulto en pesos de 2003: Variables }\end{array}$} & \multicolumn{3}{|c|}{ Hogares trabajador agrícola asalariado } \\
\hline & Estimación & Error estándar & [t-stat] \\
\hline Edad JH & -0.00246 & 0.00049 & -4.99 \\
\hline Edad al cuadrado & 0.00007 & 0.00001 & 13.39 \\
\hline Sin educación & 0.52671 & 0.00578 & 91.08 \\
\hline $\begin{array}{l}\text { Educación, pero básica incompleta } \\
(1 \text { año }<x<6 \text { años })\end{array}$ & 0.25278 & 0.00305 & 82.93 \\
\hline Número de años de escolaridad & 0.08884 & 0.00040 & 220.74 \\
\hline Si JH hombre $=1$ & 0.10185 & 0.00342 & 29.79 \\
\hline Si indígena $=1$ & -0.04882 & 0.00421 & -11.60 \\
\hline Proporción de dependencia & -0.19078 & 0.00087 & -218.75 \\
\hline Número de miembros del hogar & -0.02161 & 0.00111 & -19.49 \\
\hline $\begin{array}{l}\text { Número de miembros }>14 \\
\text { Si Ingreso agrícola }>50 \% \text { del total autónomo }\end{array}$ & -0.02447 & 0.00137 & -17.82 \\
\hline Variable $=1$ & -0.05502 & 0.00351 & -15.66 \\
\hline Si ingreso agrícola $=100 \%$ de total autónomo $=1$ & -0.40475 & 0.00226 & -179.45 \\
\hline Si urbano $=1$ & 0.01844 & 0.00197 & 9.36 \\
\hline Si JH declara en otro sector $=1$ & -0.17942 & 0.00559 & -0.17942 \\
\hline Si JH declara inactivo $=1$ & -0.03562 & 0.00312 & -0.03562 \\
\hline Si asalariado permanente $=1$ & 0.31685 & 0.00194 & 163.26 \\
\hline Constante & 11.09208 & 0.01261 & 879.98 \\
\hline
\end{tabular}

Efectos regionales (Región Metropolitana es la referencia):

Hogares trabajador agrícola asalariado

\begin{tabular}{lrrr}
\cline { 2 - 3 } dr1 & -0.08030 & 0.00970 & -8.28 \\
dr2 & -0.01423 & 0.01630 & -0.87 \\
dr3 & -0.12204 & 0.00659 & -18.51 \\
dr4 & -0.20458 & 0.00434 & -47.10 \\
dr5 & -0.13267 & 0.00376 & -35.25 \\
dr6 & -0.09418 & 0.00332 & -28.33 \\
dr7 & -0.19036 & 0.00339 & -56.20 \\
dr8 & -0.20412 & 0.00336 & -60.71 \\
dr9 & -0.20256 & 0.00451 & -44.87 \\
dr10 & -0.06721 & 0.00368 & -18.28 \\
dr11 & 0.03738 & 0.01002 & 3.73 \\
dr12 & 0.21479 & 0.00996 & 21.56 \\
\hline
\end{tabular}

$$
\begin{aligned}
& \mathrm{R}^{2}=0.5205 . \\
& \mathrm{F}(28,341795)=13248,09 . \\
& \mathrm{N}=10.773 \text { hogares trabajador asalariado. }
\end{aligned}
$$

Nota: $\mathrm{JH}=$ jefe de hogar. En contraste con las regresiones de las Tablas $\mathrm{N}^{\text {os }}$ 9, 10 y 11, la muestra incluye hogares en que el jefe es activo en otro sector y la agricultura representa más del 50\% del ingreso total autónomo del hogar. En el caso de hogares en que el jefe no es activo en la agricultura, las características de JH son las del principal generador de ingresos agrícolas. 
mente 8,4\% más para la familia agrícola independiente. Hogares de trabajadores asalariados cuyos jefes son hombres perciben mensualmente aproximadamente 10\% más per cápita que aquellos en que el jefe es mujer, y este efecto de género es casi el doble para las familias independientes.

Hay tres variables que reflejan la composición del hogar. La tasa de dependencia reduce el ingreso mensual per cápita (manteniendo el tamaño de la familia constante), y el efecto negativo es más alto para las familias de trabajadores asalariados en comparación con las familias de los independientes. El número total de miembros del hogar también reduce el ingreso per cápita familiar, pero lo reduce en casi el doble en el caso de hogares agrícolas independientes. Finalmente, a medida que el número de miembros de la familia en edad de trabajar aumenta, el ingreso per cápita disminuye y este efecto es mayor en el caso de familias de trabajadores asalariados. El resultado final es que a medida que el tamaño del hogar crece, el ingreso familiar total puede aumentar, pero no proporcionalmente ${ }^{8}$.

Un resultado particularmente interesante de esta regresión es el efecto de ser "indígena" como un determinante de ingreso en hogares agrícolas de pequeña escala: el impacto en el ingreso familiar per cápita de ser indígena en trabajadores asalariados es relativamente pequeño, y hemos ajustado por otros factores, como educación y tasa de dependencia, que podrían determinar los niveles de ingreso de las familias agrícolas indígenas ${ }^{9}$. Para el trabajador agrícola, ser indígena marca una gran diferencia en el ingreso del hogar, tomado en cuenta en escolaridad, edad, género, tasa de dependencia, región, etc. Mientras los resultados son consistentes con poca discriminación en el mercado laboral, la evidencia sugiere que algo está afectando de manera negativa —y significativa en términos económicos — el bienestar de las familias indígenas de los trabajadores agrícolas. Quizás como productores, las familias agrícolas indígenas están produciendo en tierras margina-

${ }^{8}$ Podría haber un flujo bidireccional de causa y efecto entre niveles de ingreso y tamaño del hogar: en igualdad de circunstancias, el ingreso total podría alentar a las familias a tener más niños, o bien a aceptar responsabilidad por más adultos dependientes. Podría haber retornos de escala de familias más grandes con respecto a inversiones fijas que familias más ricas pueden costear (por ejemplo, un refrigerador sirve a cuatro así como a dos personas), y las diferentes variables de costo — especialmente de niños pequeños adicionales en relación con los adultos- a medida que cambia el ingreso familiar. Esta última relación estaría considerada por el ajuste en adulto equivalente de ingreso per cápita del hogar.

${ }^{9}$ De hecho, en las especificaciones de algunas regresiones alternativas la variable “indígena” no es estadísticamente significativa al determinar el ingreso per cápita de hogares de trabajadores agrícolas asalariados. 
les, o usando tecnología menos avanzada, o vendiendo productos en mercados locales de bajo precio, o teniendo un acceso más limitado a capital de trabajo (crédito) para mejorar la tierra, tecnología o para adoptar cosechas diferentes. Quizás las restricciones de crédito obedecen a limitaciones para dar garantías (colateral) por los mismos. Desafortunadamente la información de la encuesta Casen no permite realizar una prueba de la relevancia de estas posibles explicaciones ${ }^{10}$.

Las fuentes del ingreso son importantes para determinar el ingreso per cápita familiar. Aquellas familias de trabajadores asalariados que obtienen más del $50 \%$ de su ingreso de la agricultura (pero que no dependen exclusivamente de la agricultura) perciben aproximadamente 6\% menos que una familia similar que obtiene menos del $50 \%$ de su ingreso del trabajo agrícola. Familias agrícolas cuyo ingreso autónomo proviene en más de un $50 \%$ de fuentes agrícolas (pero cuyas fuentes no son exclusivamente agrícolas) ganan sin embargo cerca de $38 \%$ más que una familia similar que obtiene menos del 50\% de su ingreso de fuentes agrícolas. Pero la dependencia del ingreso agrícola no tiene efectos lineales sobre el ingreso total autónomo de la familia agrícola.

Para la familia del trabajador asalariado que depende exclusivamente de la agricultura para su ingreso autónomo, el ingreso mensual per cápita cae un 33\% adicional, para una reducción total en el ingreso en comparación con una familia cuyo ingreso depende en menos de un $50 \%$ de la agricultura. Depender de manera exclusiva de la agricultura es similarmente dañino para las familias agrícolas independientes y para las familias de trabajadores asalariados, y casi $36 \%$ menos dañino para una familia que depende menos de la agricultura.

Simplemente observando el grado en que el ingreso promedio familiar depende de la agricultura uno podría deducir que una disminución de la dependencia podría generar mayores ingresos per cápita. Esto podría ser engañoso, por cuanto varios factores están asociados con diferencias de ingreso. La prueba de la regresión sugiere aquí fuertemente que fuentes de ingreso diversificadas (por ejemplo, pluriactividad) conducen a mayores ingresos por hogar sólo con respecto a la dependencia exclusiva en la agricultura. En igualdad de circunstancias (edad, región, educación, etc.), una familia agrícola independiente de cuatro miembros, con menos del 50\% de

${ }^{10}$ Rodrigo Cerda, en una presentación en seminario realizado en 2008 por el Centro de Estudios Públicos ("La Situación Socioeconómica Reciente de los Mapuches en la Región de la Araucanía”, 2009) reportó un análisis de los mapuches rurales y urbanos en la IX Región de Chile. Él también descubre que después de controlar por las características de los hogares no aparecen diferencias salariales inexplicables que puedan ser atribuidas a discriminación racial. 
su ingreso proveniente de fuentes agrícolas, aumenta su ingreso per cápita en el rango de 50.000 pesos por mes en comparación con familias totalmente dependientes de la agricultura para su ingreso autónomo. Ayudar al pequeño trabajador agrícola y a su familia, que dependen exclusivamente de la agricultura, a obtener trabajos fuera de la agricultura parece que incrementaría de manera considerable el bienestar del hogar.

Nótese que observamos que las familias agrícolas independientes, en promedio aquellas que obtienen más del 50\% del ingreso total de la agricultura, tienen un ingreso autónomo mensual de 341.286 pesos. Por contraste, aquellas que en promedio obtienen menos del 50\% de su ingreso de la agricultura presentan un ingreso autónomo de 538.311 pesos. Las diferencias encontradas entre ingresos promedio de dichas familias que dependen exclusivamente de la agricultura en comparación con aquellas familias con fuentes de ingreso diversificadas revelan el mismo patrón. Pero estas comparaciones de promedios no controlan por diferencias en escolaridad, edad, región y otros factores que influencian el ingreso familiar; de hecho esas comparaciones son consistentes con los resultados de la regresión. La contribución del análisis de regresión es que controla por esos otros factores y entrega un efecto parcial de la correlación de cada una de las variables con el ingreso.

Finalmente, ceteris paribus, un trabajador temporal (hombre o mujer) gana aproximadamente $27 \%$ menos que un trabajador permanente. Las explotaciones agrícolas unipersonales generan un ingreso casi $8 \%$ menor que las explotaciones agrícolas de dos a cinco trabajadores, y la presencia de un jefe oficial inactivo en el hogar hace que la familia obtenga un ingreso cerca de $8 \%$ menor que en los otros casos, así como tener un jefe de hogar activo en otro sector de la economía se traduce en un ingreso familiar 14\% menor.

Los variados resultados de las regresiones precedentes son estimaciones de efectos parciales (o marginales) de características que también aparecen en términos de las características promedio de diferentes tipos de hogar, y a través de diferentes niveles de ingreso. Los resultados de las regresiones permiten explorar el impacto en el ingreso al cambiar varias características del hogar. Una buena manera de mostrar la heterogeneidad de ingresos debido a las características del hogar consiste en variar características específicas mientras se mantienen las otras constantes.

Los efectos de la educación en el ingreso son muy fuertes, y también lo son las fuentes de ingreso diversificadas, especialmente en el caso de familias agrícolas. Con respecto a la región, podemos ilustrar un cambio de la IX Región a la V: para los casos tercero y cuarto en la Tabla $\mathrm{N}^{\mathrm{0}} 12$, el ingreso aumenta de 39.215 a 41.951 para el $\mathrm{JH}$ hombre, no indígena sin 


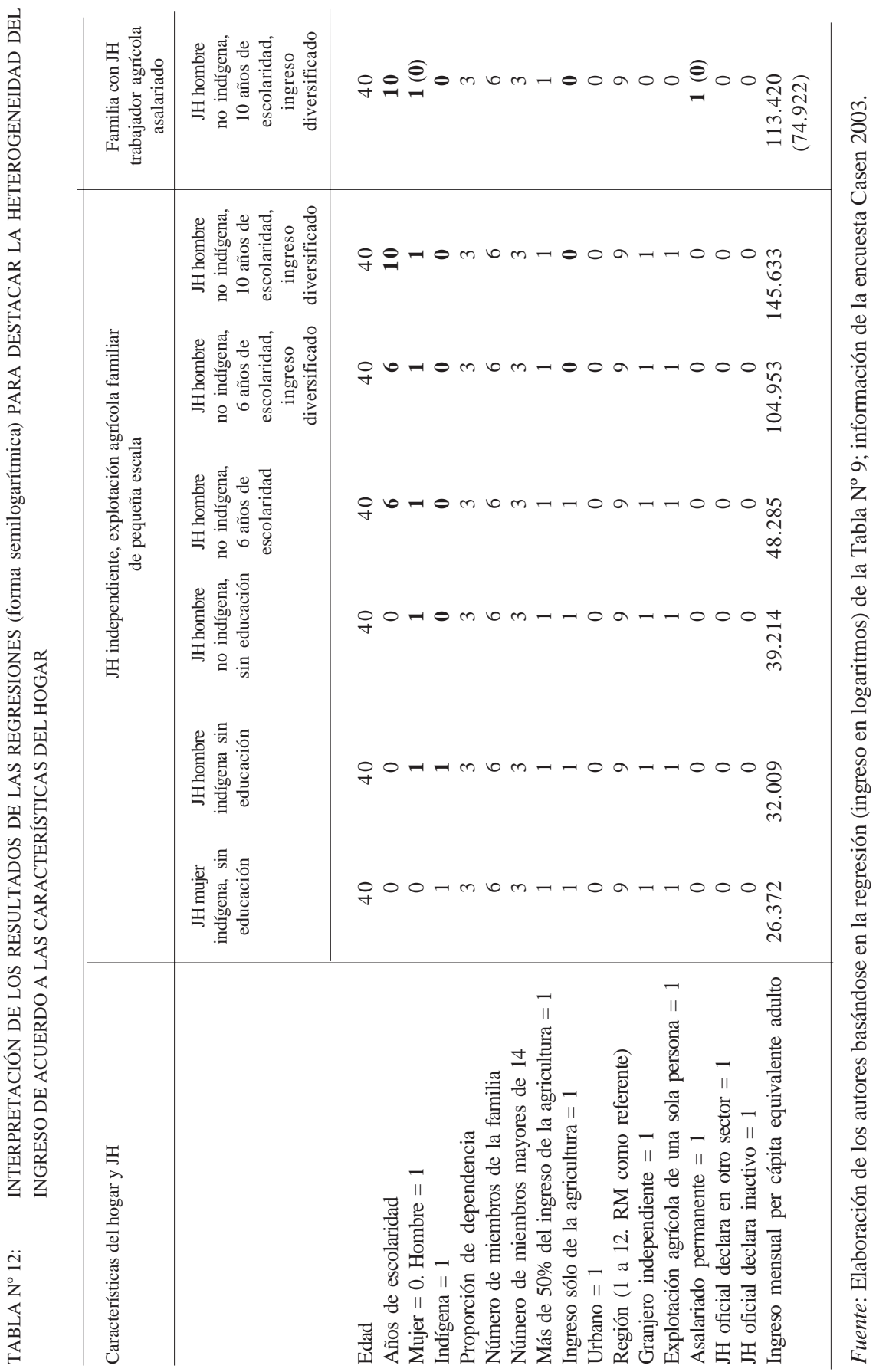


escolaridad y de 48.285 a 51.655 pesos para el JH hombre, no indígena con seis años de escolaridad. Estos cambios son relativamente pequeños. El mismo ejercicio usando los datos de la IV Región arroja ingresos más bajos en comparación con la IX y V regiones: 36.698 en el caso de la columna 3, y 45.187 pesos en el caso de la columna 4.

\section{Resumen de los resultados}

En dos tercios de los hogares agrícolas el jefe de hogar es un trabajador asalariado. Basándose en la encuesta Casen 2003, el análisis realizado muestra que de las aproximadamente 790.000 personas activas en la agricultura, cerca de 500.000 son jefes de hogar. De estos jefes de hogar, 30\% son independientes, 66\% asalariados y 4\% empleadores. La mayoría de los trabajadores asalariados se ubica en las regiones centrales del país donde la agricultura más importante es la orientada a la exportación. Pero la mayoría de los pequeños trabajadores agrícolas reside en el Sur, en sectores dedicados a la agricultura tradicional. De los independientes, casi el 60\% se encuentra en el Sur; de los trabajadores asalariados, nuevamente casi el 60\% se encuentra en la zona central. La agricultura en Chile tiene una alta proporción de la fuerza de trabajo del sector trabajando en empresas comerciales de diez o más trabajadores ${ }^{11}$.

Por al menos durante parte del año, la agricultura de gran escala es el componente mayoritario de la demanda laboral nacional del sector, especialmente en la zona central, pero también lo es en una parte importante del Sur. En el otro extremo, la explotación agrícola familiar está vinculada a trabajadores agrícolas independientes en empresas unipersonales o de dos a cinco empleados. Dichas explotaciones agrícolas emplean aproximadamente 333.000 personas, 42\% de la fuerza de trabajo agrícola. Por agricultura familiar nos estamos refiriendo a cerca de 150.000 hogares que comprenden cerca de 600.000 personas. Cerca de 50.000 de estas explotaciones agrícolas familiares corresponden a empleadores de pequeña escala, con dos a cinco trabajadores. El grupo relativamente más pobre dentro de la agricultura familiar se concentra dentro de los aproximadamente 100.000 hogares con operaciones unipersonales.

¿Quiénes son los pobres entre los hogares agrícolas? Hay más familias en pobreza o vulnerables entre los trabajadores agrícolas asalariados

${ }^{11}$ Para el total del país, el 56\% de la fuerza de trabajo no agrícola trabaja en dichas empresas, comparado con el $51 \%$ de la fuerza de trabajo agrícola. 
que el promedio nacional, y más que entre los pequeños trabajadores agrícolas independientes. Pero el lector debiera notar que entre los independientes la distribución del ingreso es mucho más dispersa (y la media se mueve hacia arriba) que entre los trabajadores asalariados, tanto en la agricultura como en otros sectores de la economía. Lo sorprendente es la alta incidencia de pobreza y vulnerabilidad entre los trabajadores agrícolas asalariados. En comparación con los trabajadores asalariados en sectores no agrícolas, la situación de ingreso del trabajador agrícola asalariado es mucho peor. El perfil de pobreza de los trabajadores agrícolas de pequeña escala es similar al de los trabajadores asalariados no agrícolas, si no levemente más agudo.

Si la política social está enfocada hacia los extremadamente pobres en la agricultura, hay cerca de 16.000 familias extremadamente pobres entre los trabajadores agrícolas asalariados, y 6.500 entre los independientes. Hay 64.000 familias adicionales en pobreza entre los trabajadores agrícolas asalariados, contra 14.000 familias adicionales entre los trabajadores independientes. Y de todas las familias de trabajadores asalariados, que hacen más del doble del número total de familias, como es el caso de los independientes, más del $45 \%$ de ellas puede ser clasificado como vulnerables o pobres.

El perfil de pobreza de la agricultura familiar que depende exclusivamente de la actividad agrícola es similar al de los trabajadores agrícolas asalariados. Una comparación relevante entre trabajadores asalariados y “familias agrícolas” es realmente entre trabajadores asalariados y familias agrícolas que son dependientes de la agricultura, porque la más alta dispersión del ingreso de trabajadores agrícolas de pequeña escala generalmente podría ser el resultado de ingresos fuera de la explotación agrícola. Uno podría esperar que los trabajadores asalariados, especialmente los trabajadores asalariados que viven en áreas urbanas, fuesen más móviles que los trabajadores agrícolas de pequeña escala cualesquiera sean sus fuentes de ingreso adicionales, pero esto parece ser inconsistente con el perfil de pobreza. Examinando este perfil de pobreza entre los trabajadores agrícolas independientes en más detalle, se advierte que la más alta variancia y media de ingresos entre ellos parece obedecer a su dependencia de fuentes no agrícolas.

De hecho, la tasa de indigencia entre familias de explotaciones agrícolas unipersonales que dependen exclusivamente del ingreso agríco- 
la es casi el doble que la de los trabajadores agrícolas asalariados. Y los hogares que dependen exclusivamente del ingreso agrícola y que están asociados a explotaciones agrícolas de empleo de pequeña escala muestran un perfil de pobreza muy similar al de los trabajadores agrícolas asalariados. Evidentemente entonces, la sola condición de ser un propietario agrícola no reduce la probabilidad de ser pobre. Atributos familiares que llevan a mejores ingresos, quizá tanto fuentes agrícolas como no agrícolas, son factores importantes. Los factores asociados con el ingreso del hogar se pueden identificar usando las ecuaciones de ingreso que permiten estimar los efectos parciales de varias variables relevantes (a partir de las regresiones mostradas en las Tablas $\mathrm{N}^{\mathrm{os}} 9,10$ y 11 ).

La educación importa. Comparados con hogares donde el JH no tiene educación formal alguna, los hogares independientes con un JH con seis años de educación perciben mensualmente en promedio un ingreso al menos 20\% más alto. Para los hogares de trabajadores asalariados, el cambio de sin educación a seis años de ella produce un aumento de ingreso de cerca del 30\%. El incremento en el ingreso del hogar derivado del aumento en los niveles de educación de seis a diez años es similar para hogares de trabajadores independientes y asalariados: cercano a un $40 \%$.

Los hogares cuyo jefe es hombre perciben más que aquellos cuyo jefe es mujer, en igualdad de circunstancias. Este efecto de género es mayor en el caso de las familias de trabajadores agrícolas independientes que en el caso de asalariados. En familias de trabajadores agrícolas independientes un $\mathrm{JH}$ hombre percibe cerca de $20 \%$ más que si es mujer; en una familia de trabajador asalariado, la ganancia es cerca de la mitad, $10 \%$. Adicionalmente, uno debiera notar que usualmente una mujer JH se asocia a una dependencia más alta —una madre soltera que trabaja. En este caso el ingreso per cápita del hogar será aún más bajo. Aún más, las mujeres asalariadas tienden a concentrarse en actividades no permanentes. Ceteris paribus, hogares con un $\mathrm{JH}$ como trabajador agrícola permanente generan $35 \%$ más de ingresos que los hogares con JH con trabajo no permanente. Un hogar de trabajador asalariado con un JH hombre, trabajando permanentemente, percibe ligeramente más del $50 \%$ que el mismo hogar con un $\mathrm{JH}$ mujer, con trabajo no permanente. Entre los hogares cuyo jefe es un trabajador asalariado con trabajo permanente, el 8,4\% son indigentes y un tercio de ellos cae bajo la línea oficial de pobreza. En otras palabras, la condición de ingreso del hogar del trabajador asalariado es determinada crucialmente por la condición del trabajo. 
Para hogares de trabajadores agrícolas independientes (por cuenta propia), la condición de ser indígena reduce el ingreso, pero sólo ligeramente para los hogares de trabajadores asalariados. Mientras la condición de jefe de hogar indígena hace que se reduzca el ingreso per cápita mensual del hogar en el caso de familias de agricultura familiar (en cerca del 5\%), esta condición se asocia con una reducción en el ingreso estadística y económicamente más significativa para la familia agrícola independiente. La condición de tener un JH indígena se encuentra en cerca del $20 \%$ de todos los hogares de pequeñas explotaciones agrícolas — cerca del $23 \%$ en el caso de operaciones unipersonales y $18 \%$ en el caso de operaciones de dos a cinco trabajadores. Esta proporción notablemente alta de hogares con JH indígena se da principalmente en el Sur, donde la mayoría de las pequeñas explotaciones agrícolas está concentrada, y más significativamente en la Novena Región. ¿Qué proporción de la población indígena es atendida por el INDAP ( $^{12}$ El Programa Orígenes estima una población objetivo potencial de 47.000 familias rurales indígenas, con una cobertura de cerca de 20.000 hogares $^{13}$.

Ayudar a aquellos pequeños trabajadores agrícolas y a sus familias que dependen exclusivamente de la agricultura aparecería como un medio para aumentar considerablemente el bienestar de esos hogares. La evidencia de las regresiones sugiere fuertemente que las fuentes de ingreso diversificadas (por ejemplo, pluriactividad) pueden conducir a ingresos más altos en los hogares, en comparación con los hogares que dependen de manera exclusiva de la agricultura. Éste no es necesariamente el caso cuando se comparan los ingresos provenientes de una mayor pluriactividad con los de los trabajadores agrícolas especializados en la agricultura, pero con algunos ingresos fuera de la explotación agrícola.

${ }^{12}$ Es curioso que el informe de mayo de 2007 del Ministerio de Agricultura sobre asistencia a la inserción competitiva de pequeñas explotaciones agrícolas no hace esfuerzo específico alguno por abordar el tema de la cuestión indígena, aunque hay una breve mención en el Programa Orígenes, un programa inter-agencial que cuenta con el patrocinio del BID.

${ }^{13}$ En 2004 la DIPRES estimó gastos netos para 2003 destinados a varias agencias gubernamentales (co-ejecutores) que sumarían aproximadamente 38.000 pesos gastados por mes por familia. Esto no implica que el hogar individual recibió dicho monto en realidad, y falta una evaluación de los beneficios netos recibidos por familia. El programa parece estar orientado a desarrollar una infraestructura institucional coordinada para tratar cuestiones relacionadas con comunidades indígenas. Después de la evolución, la DIPRES recomendó poner fin al programa diseñado originalmente y proceder a reformularlo. El programa está oficialmente bajo Mideplan. Véase Dipres: "Informe Final de Evaluación del Programa Orígenes”, 2004. 
La dependencia de la agricultura importa. En base a análisis econométricos, en igualdad de circunstancias, la pequeña familia agrícola que obtiene más del 50\% de su ingreso de la agricultura está mejor en términos de ingreso que aquellas que obtienen más del 50\% de su ingreso de fuentes no agrícolas. Pero los promedios brutos — esto es, en desigualdad de circunstancias - muestran que aquellos que obtienen menos del 50\% de su ingreso de la actividad agrícola están mejor en promedio que aquellos que obtienen más del 50\% de su ingreso de la actividad agrícola. Aquellas familias con miembros que trabajan y que presentan mayores habilidades y educación se han clasificado a sí mismas en la categoría menos dependiente de la agricultura. Moverse hacia una mayor dependencia de fuentes no agrícolas transforma a los hogares en cuasi familias de trabajadores asalariados en la agricultura, las que en promedio perciben menos ingresos. Esto quizás se debe a que el ingreso de las familias agrícolas en parte procede de retornos de capital propio en agricultura, en una proporción que probablemente varía entre los tipos de explotaciones agrícolas. Nótese que, como se aprecia en el Gráfico $\mathrm{N}^{\circ}$ 2a, los trabajadores asalariados en la agricultura tienden a obtener ingresos alrededor de una media más baja, en comparación con los trabajadores agrícolas independientes cuyos ingresos muestran una mayor dispersión y una media más alta.

¿Puede la familia agrícola que depende fuertemente del ingreso agrícola transformarse en una familia de trabajador asalariado no agrícola, que podría aumentar su ingreso? Aunque este cambio requeriría otras inversiones, como capacitación para un trabajo diferente, quizá sea posible para la mayoría de los hogares. En general, sin embargo, usando los resultados de las regresiones, la recomendación sería ayudar a las familias agrícolas a diversificar las fuentes de ingreso en tanto permanezcan en la agricultura, cuando el trabajo no agrícola mejor pagado no está disponible debido a requisitos relacionados con capacitación y educación. El análisis de la encuesta Casen muestra que la probabilidad de que el jefe de hogar de una familia agrícola en el quintil inferior de ingresos no haya completado su educación básica es de 70\%. La probabilidad de que el jefe de hogar de una familia de trabajador asalariado en la agricultura tenga el mismo nivel educacional es de 50\%. Incluso la probabilidad de no haber completado la educación básica entre los jefes de hogar de familias agrícolas en el quintil superior es de un 35\%. La implicancia para las familias agrícolas que dependen fuertemente del ingreso agrícola es que, en general, el acceso a un trabajo asalariado mejor pagado, y específicamente a un trabajo no agrícola asalariado mejor pagado, provendrá principalmente a través de la educación de su descendencia. 
Los efectos regionales importan. Los efectos regionales en el ingreso per cápita mensual para los trabajadores asalariados en todas las regiones, excepto la XI (Aysén), muestran un impacto negativo significativo estadística y económicamente en relación con la Región Metropolitana. El mayor impacto negativo aparece en las regiones IV, VIII y IX, y el menor en las regiones más al Sur, I, II, VI y XI. (Nótese que las regiones extremas tienen un costo de vida más alto, lo cual es tomado en cuenta en la información sobre el ingreso.) Después de controlar por características tales como JH indígena y educación, una familia agrícola aparece en peor situación, ceteris paribus, que las familias en la Región Metropolitana; en los casos de las regiones VII, VIII y IX, las últimas dos no son famosas por su potencial agrícola. Para familias de trabajadores agrícolas independientes, todas las regiones excepto la II y VI muestran impactos negativos sobre el ingreso, con la VIII Región (Bío Bío) teniendo el mayor impacto negativo. Es interesante notar que, tanto para familias de trabajadores asalariados como de trabajadores agrícolas independientes, la VI Región es relativamente mejor que las otras. La VI Región, inmediatamente al sur de Santiago, alberga agricultura altamente productiva orientada a las exportaciones.

Algunos comentarios finales y generales sobre el mercado del trabajo están en orden. Primero, con respecto a aumentar la demanda de empleo agroalimentario, cualquier cosa que aumente la demanda de trabajo mejorará la situación de aquellos cuyo ingreso depende de su trabajo. La continua expansión de ese empleo es de preocupación debido a los bajos retornos que han exhibido frutas y vegetales en el pasado reciente debido a la caída de la tasa de cambio, y un aumento en los salarios en términos de dólares. Hoy en día la situación se ve más promisoria, aunque con considerable incertidumbre debido a la posible caída en los precios de exportación como resultado de la crisis financiera internacional.

¿Es una contradicción que los trabajadores asalariados son más pobres pero que la creciente demanda laboral ha sido el principal motor de la reducción de la pobreza? No, no en nuestro punto de vista. Se debiera distinguir entre el nivel del cual parten los trabajadores asalariados, como grupo, y la tasa de aumento de los ingresos laborales, el empleo total y los salarios. También ha habido un efecto de selección: las familias agrícolas más pobres se han volcado hacia el trabajo agrícola asalariado (ingreso laboral), mejorando sus ingresos y reduciendo el número de trabajadores agrícolas pobres. Estos nuevos trabajadores están mejor, pero ahora son clasificados como pobres dentro de la clase trabajadora asalariada en la agricultura. 
Los hogares en que el jefe depende casi exclusivamente del trabajo de temporada presentan un complejo problema de política. Uno debiera ser cauto, sin embargo, respecto a las implicancias de los resultados precedentes sobre el trabajo no permanente. Forzar un aumento de los salarios estacionales podría ser contraproductivo, porque podría dañar tanto el empleo total como conducir a una aceleración de las tecnologías substitutivas del trabajo. Quizás una mejor solución es abocarse a extender la permanencia del trabajador en el mercado laboral —agrícola y no agrícola- y en proporcionar apoyo social. Desde el punto de vista de políticas orientadas a reducir la pobreza, quizás los temas más complejos dicen relación con los salarios agrícolas, la legislación laboral y lo que se puede hacer para ayudar a los hogares que dependen más del trabajo estacional. La legislación laboral chilena y la manera en que ella se aplica no parecen ajustarse bien a las características de la agricultura. La demanda laboral es estacional y la oportunidad del trabajo depende de la Madre Naturaleza. Aún más, los incentivos basados en la productividad — que en otras partes han probado tener éxito en la agricultura de regadío y de alto valor - son desalentados por normas diseñadas e implementadas en función del trabajo urbano. Estos importantes problemas, que rondan los mercados laborales rurales, debieran dar origen a análisis dirigidos a aumentar la productividad y los ingresos de la fuerza de trabajo agrícola.

\section{REFERENCIAS BIBLIOGRÁFICAS}

Cerda, Rodrigo (2009): “Situación Socioeconómica Reciente de los Mapuches en la Región de la Araucanía”. En Estudios Públicos, 113 (verano 2009).

Dipres (gobierno de Chile) (2004): “Informe Final de Evaluación del Programa Orígenes”.

De Ferranti, David, Guillermo Perry, William Foster, Daniel Lederman y Alberto Valdés (2005): "Beyond the City: the Rural Contribution to Development in Latin America". World Bank.

Foster, William y Alberto Valdés (2008): "Impact of High World Commodity Prices on Real Household Income of Small Farmers: Case Study for Chile”. Trabajo presentado en el XIII Congreso de Economistas Agrarios de Chile y la II Reunión Regional de Economía Agraria, Montevideo, 5 al 7 noviembre, 2008.

INE (Instituto Nacional de Estadísticas de Chile): Varias encuestas de empleo. Censo de Población de 2002. Censo Agropecuario 2007. Www.ine.cl

Melo, Óscar y Jimena López de Lérida (2006): “Evaluación del Impacto del Tratado de Libre Comercio con USA sobre la Agricultura Familiar en Chile”. FAO/BID, Universidad Católica de Chile.

Mideplan (gobierno de Chile): Encuestas Casen. Varias encuestas desde 1987.

World Bank (1997): "Chile: Poverty and Income Distribution in a High Growth Economy”. World Bank Report, № 16377. 